\title{
Kinetic Modeling of Particle Size Distribution of Soot in a Premixed Burner-Stabilized Stagnation Ethylene Flame
}

\author{
Chiara Saggese ${ }^{1,2}$, Sara Ferrario ${ }^{1}$, Joaquin Camacho ${ }^{2}$, Alberto Cuoci ${ }^{1}$, Alessio Frassoldati ${ }^{1}$, Eliseo \\ Ranzi $^{1}$, Hai Wang ${ }^{2}$, Tiziano Faravelli ${ }^{1}$ * \\ ${ }^{1}$ Department of Chemistry, Material and Chemical Engineering "Giulio Natta”, Politecnico di Milano, \\ Piazza Leonardo da Vinci 32, 20133 Milano, Italy \\ ${ }^{2}$ Mechanical Engineering Department, Stanford University, California, USA
}

\begin{abstract}
A detailed model of soot formation is proposed, which consists of a gas-phase kinetic model for the pyrolysis and oxidation of selected hydrocarbon fuels and a kinetic mechanism of soot nucleation and mass/size growth through coagulation and surface reactions. The gas-phase model (Ranzi et al., Prog. Energ Combust. Sci. 38 (2012) 468-501) was expanded to include the chemistry of Polycyclic Aromatic Hydrocarbons (PAHs) up to four-to-five ring PAHs, with a modular and hierarchical approach. The discrete sectional method was employed to solve the size evolution of the particle size distribution function (PSDF). Analogy and similarity rules were employed to describe heterogeneous reaction kinetics of soot surface reactions. A variable collision efficiency was assumed for the coalescence of small soot particles. Larger particles were assumed to undergo aggregation. The predicted PSDFs are found to be in reasonably good agreement with the experimental data for nascent soot measured in an atmospheric-pressure premixed ethylene-oxygen-argon flame in the burner-stabilized stagnation flame configuration. Sensitivity analyses of the PSDF, number density, and volume fraction were carried out with respect to the rate parameters of addition reactions of acetylene, PAHs, resonantly stabilized radical reactions, and coalescence and aggregation. The results show that the reaction of PAHs and acetylene with soot surfaces and the kinetics of coalescence and aggregation exhibit dominant effects on the detailed and global soot properties for the flame studied, in agreement with conclusions of a large range of previous modeling studies.
\end{abstract}

Keywords: soot, kinetics, burner-stabilized stagnation flame, particle size distribution

* Corresponding author

E-mail address: tiziano.faravelli@polimi.it (T. Faravelli) 


\section{Introduction}

Research into combustion based emission of polycyclic aromatic hydrocarbons (PAHs) and fine particulate matter (PM 2.5) persists due to the harmful influence on human health, environmental problems and reduction of combustion efficiency [1-3]. Critical gaps in the fundamental understanding of soot formation remain $[4,5]$. In order to describe the process of soot formation, extensive numerical and experimental studies have been conducted. So far, no direct assessment of the validity of soot models and the accompanying sub-models can be made without comparing the computational results with experimental observations of global and/or detailed properties in low-dimensional laminar flames. Past workshops have chronicled the relationship and progress made in coupled computational and experimental efforts $[6,7]$.

Development of reliable and predictive kinetic models of soot formation requires an accurate description of the gas-phase chemistry leading to gas-phase PAH formation. In addition, an appropriate coupling between gas-phase chemistry, aerosol dynamics and surface chemistry governing gas-surface reactions is necessary. As far as aerosol dynamics is concerned, there are three major approaches proposed in literature: the method of moments [8-13], the discrete sectional method [14-18] and the stochastic approach [19-24]. In this work, the discrete sectional method is applied to describe the chemistry and physics of soot nucleation and growth. Experimentally, probe sampling with scanning mobility particle sizing (SMPS) has been used to follow the evolution of soot particle size distribution function (PSDF) in flames and other reactors [25-30]. These measurements have been shown to be useful for examination of detailed soot models [31-33] that were first introduced some twenty years ago $[11,12]$. In particular, measured PSDFs offer rich information about nucleation and growth processes that can aid model improvement. For example, sensitivity analyses of the PSDF with respect to the collision efficiency [32] or particle rounding rates due to sintering and surface reactions [31] have shed new light on detailed kinetic processes of soot formation.

To minimize the problem of probe perturbation in experiments, a burner-stabilized stagnation (BSS) flame technique was used earlier to following the evolution of PSDF of nascent soot [34]. In this technique, a sampling probe is embedded in a water-cooled circular plate that acts as a flow stagnation surface. The combination reduces ambiguity in experiment and model comparisons because the flow stagnation, present in all flame probes, may be accounted for to an extent in numerical simulations. 
Lindstedt and Waldheim [35] modeled the soot PSDFs in a benchmark ethylene-oxygen-argon BSS flame [34]. A set of collision efficiencies among the nucleating species was proposed based on comparison with experimental observations. Soot measurements have been made in BSS flames of different fuels to understand how fuel structures impact the evolution of the PSDFs [36-38].

In the current work, a detailed kinetic model of soot formation and growth is presented and tested against the benchmark ethylene flame using OpenSMOKE++ software [39]. OpenSMOKE++ employs the sectional method for solving aerosol dynamics. Model predictions are compared to experimental data reported in a more recent study [40] in which the various experimental issues associated with the BSS flame sampling are addressed and new, improved data are reported. Experimental-model comparisons include temperature profiles, soot PSDFs, volume fraction and number density. More importantly, sensitivity analyses were performed for the predicted global properties and PSDFs with respect to a range of reaction processes and key results are discussed.

\section{Computational Methods}

\subsection{Gas-phase kinetic model and flame simulation}

The gas-phase kinetic model [41] adopted here consists of about 200 species and 6300 reactions. The model describes the high-temperature pyrolysis and oxidation of a wide range of hydrocarbon fuels. The reaction model was developed with a modular and hierarchical approach, and has been refined since the earlier publication. The refined model has been tested over a wide range of conditions, including pyrolysis and oxidation of benzene [42] and pyrolysis of acetylene at high temperatures [43]. The gasphase model includes the formation of PAHs from benzene to aromatic compounds larger than pyrene (e.g., 9,10-dimethyltetraphene and corannulene). Thermochemical data were obtained, where available, from Refs [44, 45]. The group additivity method [46] was used to estimate the thermochemical properties of the remaining species.

The experimental setup of BSS flame was designed for taking probe measurements of soot PSDFs on a burner-stabilized premixed flame within a flow field as well defined as possible. The sampling probe is embedded inside a circular plate. The setup creates axisymmetric flow streamlines of an impinging jet onto the surface. If the flow rate of flame gas into the sampling probe orifice is negligible, a pseudo one-dimensional formulation may be applied in numerical simulations [47]. The boundary 
condition at the burner surface is described by a uniform plug flow. The downstream boundary condition is at the burner-to-stagnation surface separation, $\mathrm{x}=H_{p}$, where the axial convective velocity vanishes. The temperature of the probe and burner is measured and these are used as temperature boundary conditions for the flame simulation. Previously established probe sampling procedures [40] were carried out to avoid diffusional particle loss and particle-particle coagulation such that the measured PSDF is insensitive to dilution. As will be discussed later, there is a minor uncertainty resulting from a non-zero sampling flow rate at the stagnation surface.

Numerical simulation of the BSS flame was performed using the OpenSMOKE++ code [39] in the pseudo one-dimensional formulation [47], with boundary conditions appropriate for the current, burnerstabilized stagnation flame problem [34]. At the stagnation surface, the boundary conditions are such that the sum of the convective and diffusive rates vanishes for the gas-phase species. For particles, the stagnation surface acts as a sink due to the thermophoretic force. The temperature was computed taking into account radiative heat losses from the gas and soot [48, 49].

\subsection{Soot model}

A discrete sectional approach is applied to solve the aerosol dynamics and surface chemistry governing soot nucleation and mass/size growth. Heavy PAHs and particle sizes are discretized into 20 classes of pseudo-species with their masses doubled from one class to the next. Each class is represented by lumped pseudo-species or BINs, each with fixed numbers of carbon and hydrogen atoms, as summarized in Table I. Thermochemical properties of the pseudo-species BINs are based on the group additivity method [46]. There is a very small impact of thermodynamic properties on predicted soot properties because the soot reactions are apparent reactions involving lumped species. The impact of the BINs thermodynamics is only evident on the thermal behavior of the system in pyrolytic conditions [43].

PAHs of more than 20 carbon atoms constitute the first four BINs, each of which is comprised of three subclasses $(A, B$ and $C$ ) with different $\mathrm{H} / \mathrm{C}$ ratios. These species are defined herein as heavy PAHs in contrast to the light PAHs up to pyrene, which are considered in the gas-phase model. The first soot particles are modeled as a cluster containing 320 carbon atoms and they are classified into BIN5. Although the choice for the first soot particles may be arbitrary, the threshold assigned is consistent with 
the observation of heavy PAHs extracted from flame-generated soot $[29,36,50,51]$ and with the particle sizes recently measured with laser-induced incandescence in low-sooting premixed flames [52]. Particles between $\mathrm{BIN}_{5}$ and $\mathrm{BIN}_{12}$ are assumed to be spherical in shape with a mass density of the particle material equal to $1.5 \mathrm{~g} / \mathrm{cm}^{3}$ [53]. $\mathrm{BIN}_{12}$ consists of particles with diameter $d_{p}$ around $10 \mathrm{~nm}$ and this BIN size also serves as the primary particle from which aggregates in larger BINs are formed [32, 53]. $\mathrm{BIN}_{13}$ to $\mathrm{BIN}_{20}$, are assumed to be monodisperse aggregates or mass fractals containing a number $N_{p}$ of $\mathrm{BIN}_{12}$ primary particles. The fractal dimension, $D_{f}$, is assumed to be 1.8 , based on values reported for nascent soot formed in a series of premixed ethylene flames [54] and for very rich sooting flames [55]. Because the experimental PSDFs were obtained by particle mobility measurement, the collision diameter $\left(d_{c}\right)$ of the aggregates was computed from the radius of gyration $R_{g}$ and compared with the measured mobility diameter:

$$
N_{p}=k_{f} \times\left(2 R_{g} / d_{p}\right)^{D_{f}} \quad \text { with } \quad k_{f}=\left(1+2 / D_{f}\right)^{D_{f} / 2}
$$

where $k_{f}$ is a constant derived from the empirical correlation of Köylü et al. [56]. Accordingly, the collision diameter is [57]:

$$
d_{c}=\sqrt{5 / 3} \times 2 R_{g}=\sqrt{5 / 3} \times d_{p} \times\left(N_{p} / k_{f}\right)^{1 / D_{f}}
$$

Dehydrogenation may occur as soot grows and ages. This process is considered here by following the kinetic evolution of subclasses of particles of different $\mathrm{H} / \mathrm{C}$ ratios in each BIN class [58]. In general, hydrogen content decreases with an increase in soot mass [59] due to both the conversion of PAHs into more peri-condensed rings and their progressive de-alkylation. In fact, experimental observations of the particle mass spectrum for nascent soot indicate that the surface may be alkylated and rich in aliphatic content $[60,61]$. Mature soot is characterized by lower aliphatic-to-aromatic $\mathrm{C}-\mathrm{H}$ ratios. Three $\mathrm{H} / \mathrm{C}$ ratios are considered for particles up to $\mathrm{BIN}_{10}$, while only two hydrogen levels are assumed for heavier BINs as shown in Fig. 1 and Table I. Two indices will be used as $\mathrm{BIN}_{i, j}$, where $i=1, \ldots, 20$ refers to the BIN class and $j(=A, B$ or $C$ ) refers to the two or three hydrogen levels, depending on the $i$ value as just discussed. For each $\mathrm{BIN}_{i, j}$ a corresponding surface radical $\left(\mathrm{BIN}_{i, j} \bullet\right)$ is also considered. Thus, we have a 
total of 100 lumped pseudo-species in 20 BINs, each of which has two or three subclasses, and moreover, each of the subclasses is further classified into radical or molecular surfaces.

Six heterogeneous reaction classes are considered:

1. Hydrogen-abstraction-carbon-addition (HACA) mechanism

2. Soot inception

3. Surface growth

4. Dehydrogenation

5. Coalescence and aggregation

6. Oxidation

Each of these heterogeneous processes is described with respect to analogous gas-phase reactions, which serve as a reference. The reference kinetic parameters are summarized in Table II along with their respective gas-phase reactions. The reference values were adjusted to account for the different species involved in each reaction, as will be described later. An automatic mechanism generator (SootGEN) was used to assemble the soot kinetic mechanism [15] and this is contained in the supplemental materials.

\subsubsection{HACA Mechanism}

The HACA mechanism contributes not only to soot inception but also to surface growth [8, 11]. Habstraction reactions by $\mathrm{H} \bullet$ and $\mathrm{OH} \bullet$ form surface radicals $\mathrm{BIN} \bullet$. Analogous to $\mathrm{PAH}$ reactions, the rate parameters of these reactions depend on the number and type of aryl C-H sites [62-64]. Reaction class 1a of Table II refers to this type of reactions, whose reference kinetics was taken from the reaction of $\mathrm{H} \bullet$ with naphthalene $\left(\mathrm{C}_{10} \mathrm{H}_{8}\right)$ :

$$
\mathrm{H} \bullet+\mathrm{C}_{10} \mathrm{H}_{8} \rightarrow \mathrm{C}_{10} \mathrm{H}_{7} \bullet+\mathrm{H}_{2}
$$

The acetylene addition to the aryl radical site completes the HACA mechanism. The reference reaction used is the acetylene addition to naphthyl radical $[65,66]$ :

$$
\mathrm{C}_{2} \mathrm{H}_{2}+\mathrm{C}_{10} \mathrm{H}_{7} \bullet \rightarrow \mathrm{C}_{12} \mathrm{H}_{9} \bullet \rightarrow \mathrm{C}_{12} \mathrm{H}_{8}+\mathrm{H} \bullet
$$

with the rate expression $1.0 \times 10^{9} \times \exp (-5(\mathrm{kcal} / \mathrm{mol}) / R T)[1 /(\mathrm{mol} \cdot \mathrm{s})]$.

An activation energy of $5 \mathrm{kcal} / \mathrm{mol}$ was assigned for acetylene addition to radical sites of heavy PAHs, particles and aggregates, while the frequency factor is adjusted for each BIN class as shown in 
Fig. 2. For $\mathrm{BIN}_{i}(i=1, \ldots, 4)$, the frequency factors are assigned the values of $1.4 \times 10^{9}$, to $1.2 \times 10^{9}$, and $1.0 \times 10^{9} 1 /(\mathrm{mol} \cdot \mathrm{s})$ for $\operatorname{BIN}_{i ; A} \bullet, \operatorname{BIN}_{i ; B} \bullet$, and $\operatorname{BIN}_{i ; C^{\bullet}}$, respectively, due to their $\mathrm{H} / \mathrm{C}$ ratio differences. These values are consistent with the gas-phase rate assignments $[8,11]$. For particles $\left(\mathrm{BIN}_{i}, i=5, \ldots, 12\right)$ and aggregates $\left(\mathrm{BIN}_{i}, i=13, \ldots, 20\right)$, the frequency factors are obtained by scaling the value of the reference reaction $\left(A_{r e f}\right.$, see Table II), taking into account particle morphology and hydrogen content. Specifically, the surface area of particles is derived from their diameter $(d)$ assuming sphericity; whereas for aggregates the entire surfaces are considered. This treatment leads to two scaling factors, one for particles:

$$
A / A_{\text {ref }}=1+\frac{d^{2} \times H / C}{d_{r e f}^{2}}
$$

and the other for aggregates:

$$
A / A_{\text {ref }}=1+\frac{N_{p} \times d_{p}^{2} \times H / C}{d_{\text {ref }}^{2}}
$$

where $d_{\text {ref }}=1.91 \mathrm{~nm}$ for the smallest particle assumed here (an average of $\mathrm{BIN}_{5}$ ).

\subsubsection{Soot inception}

As already mentioned, the first four BINs are considered as heavy gas-phase PAHs. PAH-PAH interactions result in the first soot nuclei, i.e., BIN 5 in the current model. All relevant radical-radical, radical-molecule, and molecule-molecule reactions are treated with respect to reference kinetic parameters of analogous gas-phase reactions. As an example, cyclopentadiene, cyclopentadienyl radical, benzene and phenyl radicals are the typical species of these reference reactions. The recombination of cyclopentadienyl radicals $[67,68]$ :

$$
\mathrm{C}_{5} \mathrm{H}_{5} \bullet+\mathrm{C}_{5} \mathrm{H}_{5} \bullet \mathrm{C}_{10} \mathrm{H}_{8}+2 \mathrm{H} \bullet
$$

is the reference for the recombination of two resonantly stabilized radicals with its rate expression given by $1.0 \times 10^{9} \times \exp (-6(\mathrm{kcal} / \mathrm{mol}) / R T)[1 /(\mathrm{mol} \cdot \mathrm{s})]$. The recombination of the cyclopentadienyl radicals is barrierless, but the subsequent isomerization of the adduct forming the precursor to nathphalene requires a substantial energy barrier. In general, the energy barrier of molecular weight growth reactions 
resulting from radical-radical combination followed by the isomerization of the adduct is highly dependent on the nature of the reactants. In the model, we assume that the activation energy is 3 $\mathrm{kcal} / \mathrm{mol}$ if one of the two recombining radicals is resonantly stabilized, and $0 \mathrm{kcal} / \mathrm{mol}$ if neither is resonantly stabilized, as discussed by Djokic et al. [68]. For radical-molecule reactions, we consider the reaction between phenyl and ethynylbenzene as the reference reaction:

$$
\mathrm{C}_{6} \mathrm{H}_{5} \bullet+\mathrm{C}_{8} \mathrm{H}_{6} \rightarrow \mathrm{C}_{14} \mathrm{H}_{10}+\mathrm{H} \bullet
$$

where $\mathrm{C}_{14} \mathrm{H}_{10}$ is a lumped species (phenanthrene and anthracene), with the corresponding rate expression given as $1 \times 10^{9} \times \exp (-8(\mathrm{kcal} / \mathrm{mol}) / \mathrm{RT})[1 /(\mathrm{mol} \cdot \mathrm{s})]$ [68]. Again, the activation energy is assumed to increase to $19 \mathrm{kcal} / \mathrm{mol}$ for resonantly stabilized radicals. Finally, molecule-molecule collisions leading to van der Waals interactions from pyrene up to $\mathrm{BIN}_{4}[69,70]$ are given with the rate constant of $1.0 \times 10^{6} \times T^{0.5}[1 /(\mathrm{mol} \cdot \mathrm{s})][71]$ and the reaction is written as:

$$
\begin{aligned}
& \mathrm{C}_{16} \mathrm{H}_{10}+\mathrm{C}_{16} \mathrm{H}_{10} \rightarrow \mathrm{C}_{32} \mathrm{H}_{20} \rightarrow 0.4\left[\mathrm{BIN}_{1}\right]+0.6\left[\mathrm{BIN}_{2}\right] \\
& \rightarrow 0.1667 \mathrm{BIN}_{1,1}+0.2333 \mathrm{BIN}_{1,2}+0.25 \mathrm{BIN}_{2,1}+0.35 \mathrm{BIN}_{2,2}
\end{aligned}
$$

Stoichiometric coefficients of the above reaction are derived using linear interpolation (lever rule) and C-H conservation. As already mentioned, all interactions among BINs up to $\mathrm{BIN}_{4}$ and the radicals of the light gas phase PAHs, up to pyrene, are considered in this reaction class. For simplicity, the stoichiometric coefficients of reaction products and the $j$ index of BINs are omitted in Table II. According to chemical kinetics and aerosol dynamics theory [72], we scale the actual frequency factors by the change in collision frequency $\left(C_{f}\right)$ relative to that of the reference reaction $\left(C_{f, r e f}\right)$. Specifically, for each BIN the pre-exponential factor is estimated by

$$
A / A_{\text {ref }}=C_{f} / C_{f, \text { ref }}
$$

where

$$
C_{f}=\sigma^{2} \sqrt{\frac{8 \pi k T}{\mu}}
$$

$k$ is the Boltzmann constant, $\mu$ is the reduced mass, $\sigma$ is the collision diameter. The reference collision frequency is calculated using the parameters of the colliding partners of the respective reaction listed in 
Table II, while the actual collision frequency is obtained using the median values corresponding to each BIN.

\subsubsection{Surface growth}

In addition to the HACA Mechanism, small resonantly stabilized radicals, like propargyl $\left(\mathrm{C}_{3} \mathrm{H}_{3} \bullet\right)$, ethylnyl-1-vinyl $\left(\mathrm{CH} \equiv \mathrm{C}-\mathrm{C} \bullet=\mathrm{CH}_{2}\right.$ or $\left.i-\mathrm{C}_{4} \mathrm{H}_{3} \bullet\right), 1,3$-butadien-2-yl $\left(\mathrm{CH}_{2}=\mathrm{C} \bullet-\mathrm{CH}=\mathrm{CH}_{2}\right.$ or $i$ - $\left.\mathrm{C}_{4} \mathrm{H}_{5} \bullet\right)$ and cyclopentadienyl $\left(\mathrm{C}_{5} \mathrm{H}_{5} \bullet\right)$ contribute to soot growth through addition reactions with all BINs (radicals and non-radicals). These resonantly stabilized radicals are referred to as RR • in Table II. Their additions to $\mathrm{C}_{6} \mathrm{H}_{5} \bullet$ or $\mathrm{C}_{6} \mathrm{H}_{6}$ are considered as reference reactions, as shown for propargyl radicals:

$$
\begin{aligned}
& \mathrm{C}_{3} \mathrm{H}_{3} \bullet+\mathrm{C}_{6} \mathrm{H}_{5} \bullet \rightarrow \mathrm{C}_{9} \mathrm{H}_{8} \\
& \mathrm{C}_{3} \mathrm{H}_{3} \bullet+\mathrm{C}_{6} \mathrm{H}_{6} \rightarrow \mathrm{C}_{9} \mathrm{H}_{8}+\mathrm{H}^{\bullet}
\end{aligned}
$$

The kinetic parameters specific for each radical are derived from reference values, again accounting for the change in the collision frequency largely because of the increase in the collision diameters of the particles and aggregates.

The same addition reactions on soot particles and aggregates are also extended to PAH radicals. Their kinetic parameters, being slightly different between light (up to pyrene) and heavy PAH radicals $\left(\mathrm{BIN}_{i}, i=1, \ldots, 4\right)$, are derived from the asymptotic values of the reference addition reactions on $\mathrm{BIN}_{20}$ reported in Table II. In agreement with experimental observations [73], the reference kinetic parameters are multiplied by a collision efficiency $\gamma$ which depends on the collision diameter as given below:

$$
k=A_{\text {ref }} \times T^{0.5} \times \gamma(\sigma)=A_{\text {ref }} \times T^{0.5} \times \frac{100+\sigma^{6.5}}{10^{5}+\sigma^{6.5}}
$$

Figure 3 presents a comparison between the correlation proposed here and experimental collision efficiency reported by D'Alessio et al. [73]. The correlation gives slightly higher values for the collision efficiency than the experiment, but lower than those suggested by Raj et al. [74]. A sensitivity analysis of the computed soot properties to the collision efficiency will be discussed later.

\subsubsection{Dehydrogenation}

Heavy PAHs and soot particles can undergo dehydrogenation by molecular and radical pathways. As discussed before, two or three hydrogenation levels are considered for different BINs. The PAH and 
soot particles can evolve to less hydrogenated BINs as the growth and aging occur. The reference reaction for radical dehydrogenation is the fluorene formation from the benzyl-2-phenyl radical [15] :

$$
\mathrm{C}_{13} \mathrm{H}_{11} \bullet \rightarrow \mathrm{C}_{13} \mathrm{H}_{10}+\mathrm{H} \bullet
$$

The reaction of di-phenyl-methane to give fluorene [75] is the reference dehydrogenation reaction for non-radical BINs:

$$
\mathrm{C}_{6} \mathrm{H}_{5} \mathrm{CH}_{2} \mathrm{C}_{6} \mathrm{H}_{5} \rightarrow \mathrm{C}_{13} \mathrm{H}_{10}+\mathrm{H}_{2}
$$

The frequency factor of these reactions accounts for the number of hydrogen atoms of the reactant BIN. $\mathrm{H}$-addition reactions on molecular species and successive de-methylation, also called the ipso-addition reaction, further promote dehydrogenation. Again, the kinetic parameters are taken from the similar reactions of light aromatics [76], i.e.,

$$
\mathrm{CH}_{3} \mathrm{C}_{10} \mathrm{H}_{7}+\mathrm{H} \bullet \rightarrow \mathrm{C}_{10} \mathrm{H}_{8}+\mathrm{CH}_{3} \bullet
$$

The reference rate constant is scaled on the basis of the reactant $\mathrm{H} / \mathrm{C}$ ratio, while BINs with $\mathrm{H} / \mathrm{C}$ ratio lower than 0.3 are assumed to not take part in this reaction path because of the negligible degree of methylation of these species. At very high temperatures, surface radicals can be generated also from C$\mathrm{H}$ fission and kinetic parameters are derived from the reference reaction [42]:

$$
\mathrm{C}_{6} \mathrm{H}_{6} \rightarrow \mathrm{C}_{6} \mathrm{H}_{5} \bullet+\mathrm{H} \bullet
$$

Again, the frequency factor is adjusted to account for the reactant hydrogen level.

\subsubsection{Coalescence and aggregation}

Particle coalescence and aggregation heavily influence the time evolution of particle size distribution $[11,12,32,77]$. In the current model, particle coalescence is considered only for particleparticle $\left(\mathrm{BIN}_{i}, i=5, \ldots, 12\right)$ interactions. Particle aggregation involves the interactions among soot aggregates $\left(\mathrm{BIN}_{i}, i=13, \ldots, 20\right)$, while particle-aggregate interactions $\left(\mathrm{BIN}_{i}, i=5, \ldots, 12\right.$ interacting with $\left.\mathrm{BIN}_{i}, i=13, \ldots, 20\right)$ occur through a 'soft' aggregation, that could be considered as the coalescence of a particle onto an aggregate. The rate constants of coalescence and aggregation are determined in the same manner of PAH addition to soot surface: multiplying the pre-exponential factor by a collision efficiency, while the activation energy is assumed to be zero. An asymptotic reference frequency factor 
of $2 \times 10^{11} 1 /(\mathrm{mol} \cdot \mathrm{s})$ is assumed for the coalescence among soot particles. As shown in Fig. 4, the correlation for the collision efficiency adopted here,

$$
\gamma=\frac{100+\sigma^{8.5}}{10^{5}+\sigma^{8.5}}
$$

is higher than the one assumed for PAH radicals addition to BINs (Fig. 3).

A reference value of $1.5 \times 10^{11} 1 /(\mathrm{mol} \cdot \mathrm{s})$ was assumed for both particle-aggregate interactions and aggregation. The kinetic parameter for coalescence and aggregation agree with those proposed by Sirignano et al. [32]. For species heavier than $\mathrm{BIN}_{4}$, the coalescence and aggregation kinetic parameters are identical between radicals and non-radicals, and these are provided in Table II.

\subsubsection{Oxidation}

While the complexity of soot inception and size/mass growth kinetics can be overwhelming, the kinetics of soot oxidation is even less defined. Soot oxidation rates are expected to strongly depend on the structure, age and morphology of soot [78]. Here, several soot oxidation reactions are considered:

\footnotetext{
1. oxidation of BIN molecules and radicals by $\mathrm{OH} \bullet$

2. $\quad$ oxidation of BIN molecules and radicals by $\mathrm{O} \bullet$

3. oxidation of BIN radicals by $\mathrm{O}_{2}$.
}

Kinetic parameters are again derived from similar gas-phase reactions, as shown in Table II. Additionally, oxidation-induced, particle fragmentation [32] was considered but its effect on properties of soot predicted under the condition of the flame tested is negligible. $\mathrm{HO}_{2} \bullet$ oxidation reactions, derived from the reaction of $\mathrm{HO}_{2} \bullet$ with indenyl radical [79], prove to be also negligible under the condition tested.

\section{Comparison of Model Predictions and Experimental Data}

\subsection{BSS Ethylene Flames}

Properties of soot measured in Flame C3 [40] are chosen as the test case for the model discussed above. In that study, soot was generated in a $16.3 \%$ ethylene-23.7\% oxygen-argon BSS flame at atmospheric pressure (Flame C3 of Ref [80]). The cold gas velocity is $8 \mathrm{~cm} / \mathrm{s}$ (298 $\mathrm{K}$ and $1 \mathrm{~atm})$. The soot was sampled along the centerline of the flame at the stagnation surface. The diluted soot aerosol 
was analyzed over a range of burner-to-stagnation surface separations by a scanning mobility particle sizer for their PSDFs. Volume fraction and number density of particles with mobility diameter $D_{m}>2.4$ $\mathrm{nm}$ were obtained from the detailed PSDF.

In the BSS flame setup, each sampling position represents a different flame even if the inlet conditions are the same, because the temperature and velocity profiles change with the burner-tostagnation surface separation. In fact, all probe sampling techniques, including GC microprobes and molecular beam mass spectrometry, should have treated each probing position as a unique flame, since each probe position constitutes a unique boundary condition. For the BSS flame setup, the flow field may be approximated as a diverging stagnation flow.

Comparison between experimental and computed temperature profiles is shown in Fig. 5 for a series of burner-to-stagnation separations, $H_{p}$. The maximum temperature is all around $1830 \mathrm{~K}$, but the burned gas is cooled off at different rate depending on the $H_{p}$ value. Overall, the model reproduces the experimental temperature profiles within their uncertainties. The simulations consider heat losses due to radiation of gas-phase species and soot particles. Neglecting radiative heat loss would cause an overprediction of the temperature in the post-flame region, as shown by the dashed line in Fig. 5 .

We carried out a simulation for $H_{p}=1.0 \mathrm{~cm}$, comparing the results with and without the Soret effect, as shown in Fig. 6. As expected, the Soret effect serves mostly to lower the $\mathrm{H}_{2}$ concentrations in the cold regions of the flame, i.e., the unburned mixture just exiting the burner and the spatial region close to the stagnation surface. The Soret effect also impacts the concentrations of aromatics, as shown in Fig. 7, and it increases the concentration of these species towards the cold stagnation surface region, by about $10 \%$. A very similar effect can be observed also in the flames with different separation distances, $H_{p}$.

Thermophoresis is a special case of the Soret effect acting on particles. Under a given temperature gradient $\nabla T$, the drift velocity may be expressed approximately by [81]:

$$
V_{k}^{(T h)}=-0.538 v \frac{\nabla T}{T}
$$

where $v$ is the kinematic viscosity of the gas mixture. Figure 8 examines the influences of the Soret effect and thermophoresis on the mole fraction profiles computed for particles for $H_{p}=1.0 \mathrm{~cm}$. The effect leads to a somewhat reduced particle concentration because the temperature gradient and drift 
velocity near the stagnation surface reduce the particle residence time and limit particle mass/size growth.

In order to identify key intermediates and main pathways to soot, Fig. 9 shows an analysis of rate of production computed for $H_{p}=1.0 \mathrm{~cm}$. Ethylene mainly forms the vinyl radical, which undergoes beta scission to form acetylene. Propyne is produced from acetylene as it reacts with $\mathrm{CH}_{3} \bullet$ and $\mathrm{CH}_{2} \bullet$, followed by production of the propargyl radical by $\mathrm{H}$-abstraction. The key step for phenyl production is the self-reaction of two propargyl radical. The reaction of acetylene with phenyl radical forms phenylacetylene, which subsequently leads to the production of naphthalene and heavier PAHs largely through the HACA mechanism.

Comparisons of experimental and computed soot volume fraction, $F_{v}$, and number density, $N$, are shown in Fig. 10 over the range of $H_{p}$ studied. The number density is defined to be the particles with mobility diameter larger than $2.4 \mathrm{~nm}$ as this is the lower detection limit of the SMPS. The BSS configuration has been examined in a 2-D flow simulation to quantify the perturbation to the flow field due to a finite pressure drop which drives the soot sample into the probe orifice [40]. The simulation suggests that the flow velocity perturbs the flame such that the measured PSDF may not correspond to a single sampling point at the stagnation surface but rather it is an averaged PSDF corresponding to a small volume surrounding the probe orifice. To account for this possibility, we also present in Fig. 10 the computed results at $0.2 \mathrm{~cm}$ upstream of the burner-to-stagnation surface separation (dashed lines). The agreement between experimental data and model predictions is reasonably good even though the model appears to over-predict soot volume fraction towards large $H_{p}$ values.

At a detailed level, the model reproduces the evolution of the particle size distributions rather well from nucleation to later stages of mass/size growth, as shown in Fig. 11. Again, we present the PSDFs computed at the stagnation surface (solid lines) and $0.2 \mathrm{~cm}$ beneath the surface (dashed lines). The model predicts the overall progression of the mobility PSDFs. Nucleation size particles are observed at $H_{p}=0.40 \mathrm{~cm}$ and a shoulder appears later. For $H_{p}=1.2 \mathrm{~cm}$, the predicted PSDF shows a tail on the small size side along with a lognormal-like PSDF on the large size side, both are in qualitative agreement with the measurements.

As discussed before, the model over-predicts the soot volume fraction for large $H_{p}$ values. The cause for the discrepancy could be attributed, at least in part, to the wall boundary condition at the stagnation 
surface. In the model, soot calculated at the stagnation surface is mostly the result of thermophoresis, whereas in the actual experiment, a finite orifice flow causes a substantially shorter residence time for the particles some 0.1 to $0.2 \mathrm{~cm}$ in front of the orifice. As shown in Fig. 11, PSDFs "sampled" from the simulated results at the stagnation surface and $0.2 \mathrm{~cm}$ beneath the surface show some notable differences. The shortened residence time gives better agreement in terms of the median particle size, even though the particle number density is generally over-predicted by the model. Despite this uncertainty, comparisons of the measured PSDFs and model predictions yield useful information about the model. For example, the computed number density is contributed heavily from small particles. Thus, the over-prediction of the number density towards large $H_{p}$ (Fig. 10) is clearly caused by an overestimated nucleation strength as seen in the bottom panels of Fig. 11. However, following Eaves et al. [82], the nucleation reversibility accounted by introducing the reverse reactions of HACA mechanism, proves to be negligible under the investigated conditions.

Another source of uncertainty in the comparison between experiments and model predictions could be the interpretation of the measured mobility diameter. As discussed in Camacho et al. [40], the measured mobility diameter is effectively derived from the collision cross-section of the particle with the surrounding gas. The true size and shape of nascent soot cannot be determined from mobility sizing and in this work the comparison is made on the basis of an equivalent sphere. Further experimental insights into the aggregate fractal nature could help to improve the interpretation of the soot measurements.

\subsection{Sensitivity Analysis}

Sensitivity analyses were carried out using the brute force method to examine the dependency of the global and detailed sooting behaviors on the various model processes. Selected results are reported here. All analyses were performed in terms of the reaction classes discussed above with the relevant rate constant perturbed by a factor of 10 . The analyses were made for two $H_{p}$ values, 0.55 and $1.0 \mathrm{~cm}$, which correspond to nucleation and agglomeration stages, respectively.

Table III shows the five computational test cases to be discussed here. The rate of acetylene addition to the soot surface is increased and decreased by a factor of 10 in Cases Ia and Ib; an enhanced PAH addition rate constant is considered in Case II; Case III evaluates an increased rate of resonantly 
stabilized species $\left(\mathrm{C}_{3} \mathrm{H}_{3} \bullet\right.$ and $\left.\mathrm{C}_{5} \mathrm{H}_{5} \bullet\right)$ based soot mass growth; and Case IV assesses an increased rate of particle-particle coalescence and aggregation. Results are shown in Figs. 12 and 13 for volume fraction and number density and detailed PSDFs, respectively.

Surface reactions of $\mathrm{C}_{2} \mathrm{H}_{2}$ and PAHs (Cases I and II) appear to have the heaviest influence on soot volume, as shown in Fig. 12. BIN radicals, due to their stability, are still present in the post-flame region, and hence, acetylene addition on them remains active. Additionally, H-abstraction reactions of soot surfaces remain active in the post-flame region, despite the substantially lower concentrations of $\mathrm{H} \cdot$, vinyl or methyl radicals than in the flame region. An inspection of Fig. 13 shows that both processes promote soot mass growth. Increases in the rate constant of $\mathrm{C}_{2} \mathrm{H}_{2}$ - and $\mathrm{PAH}$-surface reactions increase the particle size in both stages of soot growth, although a faster PAH-surface reaction also depletes the PAHs and leads to a reduced particle nucleation. The resonantly stabilized species are calculated to have little impact on soot growth for the flame tested. While the gas-surface processes just discussed can have varying influence on the particle volume and mass, none impacts the number density drastically. In contrast, increasing particle coalescence and aggregation rates lowers the number density, increases the particle size, and lowers the volume fraction as these processes decreases the particle surface area. As shown in Figs. 10 and 11, the current model over-predicts the soot volume fraction and particle size to an extent. Lowering the reaction rate constants of $\mathrm{C}_{2} \mathrm{H}_{2}$-surface reactions (Case $\mathrm{Ib}$ ) appears to give a better agreement for the volume fraction. Adjustments to the rate constants were not attempted in the current work, as our primary interest is to examine the combined effect of the model parameters assigned on model predictions without arbitrary adjustment. Improvements of the model can certainly be made when the same model is subject to tests over a wider range of flames of different fuels, flame temperature and reactant stoichiometry.

In order to investigate the coalescence and aggregation processes further, a sensitivity analysis was made for the different kinetic processes leading to particle-particle coalescence, particle-aggregate coalescence, and aggregation (reaction classes 5a, 5b and 5c of Table II), as summarized in Table IV. In all cases, the pre-exponential factors are perturbed by a few factors. The results are shown in Fig. 14 for volume fraction and number density and Fig. 15 for PSDFs. For both $H_{p}$ values tested, the soot volume fraction is hardly impacted by these particle-particle processes. However, they can impact the number 
density and the PSDF shapes quite drastically. For example, an increase in the rate of particle coalescence on aggregates deepens the trough and moves it towards larger particle size.

\section{Conclusions}

A soot model is proposed by coupling a detailed gas-phase chemical kinetic model of hydrocarbon fuel pyrolysis and oxidation with fundamental processes of soot nucleation, and mass and size growth. A discrete sectional method was employed to solve aerosol dynamics. The predicted soot volume fraction, number density and detailed particle size distribution functions were compared with observations made in a burner-stabilized stagnation flame of ethylene, oxygen and argon. The model is shown to reproduce the experimentally observed bimodal size distribution and its evolution, from particle inception to later-stages of mass and size growth. The model was found to over-predict the rate of surface growth, leading to somewhat larger volume fractions and particle sizes than the experimental data. Considering the significant model parameter uncertainties and difficulties to match the experimental boundary conditions exactly, the agreement is satisfactory. Surface growth reactions with acetylene and PAHs were found to have the greatest impact on the soot volume fraction, in agreement with conclusions reached in earlier modeling studies. For the flame tested, mass growth from surface reaction of resonantly stabilized species was found to be insignificant. Particle coalescence and aggregation processes impact the number and the detailed shapes of the size distribution. Further improvements of the reaction model may be accomplished by testing it against flames of different fuels, temperature and reactant stoichiometry.

\section{Acknowledgements}

Authors gratefully acknowledge and remember the pioneering and inspiring discussions with Adel Sarofim and Antonio D'Alessio. Work at Stanford was supported by the Combustion Energy, Frontier Research Center (CEFRC), an Energy Frontier Research, Center funded by the U.S. Department of Energy, Office of Science, Office of Basic Energy Sciences under Award Number DESC0001198. 


\section{References}

1. N.A.H. Janssen, G. Hoek, M. Simic-Lawson, P. Fischer, L. van Bree, H. ten Brink, M. Keuken, R.W. Atkinson, H.R. Anderson, B. Brunekreef, F.R. Cassee, Environ. Health Perspect. 119 (2011) 1691-1699.

2. T.C. Bond, S.J. Doherty, D.W. Fahey, P.M. Forster, T. Berntsen, B.J. DeAngelo, M.G. Flanner, S. Ghan, B. Karcher, D. Koch, S. Kinne, Y. Kondo, P.K. Quinn, M.C. Sarofim, M.G. Schultz, M. Schulz, C. Venkataraman, H. Zhang, S. Zhang, N. Bellouin, S.K. Guttikunda, P.K. Hopke, M.Z. Jacobson, J.W. Kaiser, Z. Klimont, U. Lohmann, J.P. Schwarz, D. Shindell, T. Storelvmo, S.G. Warren, C.S. Zender, J. Geophys. Res.-Atmos. 118 (2013) 5380-5552.

3. $\quad$ D.R. Tree, K.I. Svensson, Prog. Energy Combust. Sci. 33 (2007) 272-309.

4. A. D'Anna, Proc. Combust. Inst. 32 (2009) 593-613.

5. H. Wang, Proc. Combust. Inst. 33 (2011) 41-67.

6. H. Bockhorn, Soot Formation in Combustion: Mechanisms and Models, Springer-Verlag, Berlin, 1994.

7. H. Bockhorn, A. D'Anna, A. F. Sarofim, H. Wang, Combustion Generated Fine Carbonaceous Particles, KIT Scientific Publishing, Karlsruhe, 2009.

8. M. Frenklach, Phys. Chem. Chem. Phys. 4 (2002) 2028-2037.

9. G. Blanquart, H. Pitsch, Combust. Flame 156 (2009) 1614-1626.

10. G. Blanquart, H. Pitsch, in: H. Bockhorn, A. D’Anna, A. Sarofim, H. Wang (Eds.), Combustion Generated Fine Carbonaceous Particles, KIT Scientific Publishing, 2009, pp 437-463.

11. M. Frenklach, H. Wang, Proc. Combust. Inst. 23 (1991) 1559-1566.

12. M. Frenklach, H. Wang, in: H. Bockhorn (Ed.), Soot formation in combustion: Mechanisms and Models, Springer-Verlag, 1994, pp 165-192.

13. M. Frenklach, S.J. Harris, J. Colloid Interf. Sci. 118 (1987) 252-261.

14. S. Granata, F. Cambianica, S. Zinesi, T. Faravelli, E. Ranzi, in: Proceedings of the European Combustion Meeting, April, 2005, Louvain-la-Neuve, Belgium, paper 035.

15. H. Richter, S. Granata, W.H. Green, J.B. Howard, Proc. Combust. Inst. 30 (2005) 1397-1405.

16. R. Hall, M. Smooke, M. Colket, in: F. Dryer, R. Sawyer (Eds), Physical and Chemical Aspects of Combustion: A Tribute to Irvin Glassman, Gordon and Breach, 1997, pp 189-230.

17. M. Smooke, C. McEnally, L. Pfefferle, R. Hall, M. Colket, Combust. Flame 117 (1999) 117-139.

18. C.J. Pope, J.B. Howard, Aerosol Sci. Tech. 27 (1997) 73-94.

19. M. Balthasar, M. Kraft, Combust. Flame 133 (2003) 289-298. 
20. J. Singh, M. Balthasar, M. Kraft, W. Wagner, Proc. Combust. Inst. 30 (2005) 1457-1465.

21. M. Celnik, R. Patterson, M. Kraft, W. Wagner, Combust. Flame 148 (2007) 158-176.

22. M. Goodson, M. Kraft, J. Comput. Phys. 183 (2002) 210-232.

23. M. Sander, R.I. Patterson, A. Braumann, A. Raj, M. Kraft, Proc. Combust. Inst. 33 (2011) 675683.

24. A. Violi, S. Izvekov, Proc. Combust. Inst. 31 (2007) 529-537.

25. M.M. Maricq, S.J. Harris, J.J. Szente, Combust. Flame 132 (2003) 328-342.

26. B. Zhao, Z. Yang, M.V. Johnston, H. Wang, A.S. Wexler, M. Balthasar, M. Kraft, Combust. Flame 133 (2003) 173-188.

27. B. Öktem, M.P. Tolocka, B. Zhao, H. Wang, M.V. Johnston, Combust. Flame 142 (2005) $364-$ 373.

28. S.L. Manzello, D.B. Lenhert, A. Yozgatligil, M.T. Donovan, G.W. Mulholland, M.R. Zachariah, W. Tsang, Proc. Combust. Inst. 31 (2007) 675-683.

29. L. Sgro, A. Barone, M. Commodo, A. D’Alessio, A. De Filippo, G. Lanzuolo, P. Minutolo, Proc. Combust. Inst. 32 (2009) 689-696.

30. C.A. Echavarria, A.F. Sarofim, J.S. Lighty, A. D’Anna, Proc. Combust. Inst. 32 (2009) 705-711.

31. D. Chen, Z. Zainuddin, E. Yapp, J. Akroyd, S. Mosbach, M. Kraft, Proc. Combust. Inst. 34 (2013) $1827-1835$.

32. M. Sirignano, J. Kent, A. D’Anna, Energy Fuel. 27 (2013) 2303-2315.

33. A. D’Anna, M. Sirignano, J. Kent, Combust. Flame 157 (2010) 2106-2115.

34. A.D. Abid, J. Camacho, D.A. Sheen, H. Wang, Combust. Flame 156 (2009) 1862-1870.

35. R.P. Lindstedt, B.B.O. Waldheim, Proc. Combust. Inst. 34 (2013) 1861-1868.

36. A. Abid, E. Tolmachoff, D. Phares, H. Wang, Y. Liu, A. Laskin, Proc. Combust. Inst. 32 (2009) 681-688.

37. J. Camacho, S. Lieb, H. Wang, Proc. Combust. Inst. 34 (2013) 1853-1860.

38. K.V. Puduppakkam, A.U. Modak, C.V. Naik, J. Camacho, H. Wang, E. Meeks in: ASME Turbo Expo 2014: Turbine Technical Conference and Exposition, June, 2014, Düsseldorf, Germany, paper GT2014-27123.

39. A. Cuoci, A. Frassoldati, T. Faravelli, E. Ranzi, Comput. Phys. Commun. 192 (2015) 237-264.

40. J. Camacho, C. Liu, C. Gu, H. Lin, Z. Huang, Q. Tang, X. You, C. Saggese, Y. Li, H. Jung, L. Deng, I. Wlokas, H. Wang, Combust. Flame, submitted. 
41. E. Ranzi, A. Frassoldati, R. Grana, A. Cuoci, T. Faravelli, A.P. Kelley, C.K. Law, Prog. Energy Combust. Sci. 38 (2012) 468-501.

42. C. Saggese, A. Frassoldati, A. Cuoci, T. Faravelli, E. Ranzi, Combust. Flame 160 (2013) 11681190.

43. C. Saggese, N.E. Sánchez, A. Frassoldati, A. Cuoci, T. Faravelli, M.U. Alzueta, E. Ranzi, Energy Fuel. 28 (2014) 1489-1501.

44. A. Burcat, B. Ruscic, Third millenium ideal gas and condensed phase thermochemical database for combustion with updates from active thermochemical tables, Argonne, IL: Argonne National Laboratory, 2005.

45. R. J. Kee, F. M. Rupley, J. A. Miller, CHEMKIN-II: A FORTRAN Chemical Kinetics Package for the Analysis of Gas-Phase Chemical Kinetics, Albequerque, NM, SAND89-8009, 1989.

46. S.W. Benson, Thermochemical kinetics (2nd Ed.), John Wiley, New York, 1976.

47. M. Smooke, I. Puri, K. Seshadri, Proc. Combust. Inst. 21 (1986) 1783-1792.

48. W.L. Grosshandler, RADCAL: A narrow-band model for radiation calculations in a combustion environment, NIST Technical Note 1402, Gaithersburg, MD, 1993.

49. S. Sazhin, An approximation for the absorption coefficient of soot in a radiating gas, Fluent Europe Ltd. (Internal Report), 1994.

50. L. Sgro, A. De Filippo, G. Lanzuolo, A. D’Alessio, Proc. Combust. Inst. 31 (2007) 631-638.

51. A.L. Lafleur, K. Taghizadeh, J.B. Howard, J.F. Anacleto, M.A. Quilliam, J. Am. Soc. Mass Spectr. 7 (1996) 276-286.

52. H. Bladh, N.-E. Olofsson, T. Mouton, J. Simonsson, X. Mercier, A. Faccinetto, P.-E. Bengtsson, P. Desgroux, Proc. Combust. Inst. 35 (2015) 1843-1850.

53. B. Zhao, K. Uchikawa, H. Wang, Proc. Combust. Inst. 31 (2007) 851-860.

54. M. Schenk, S. Lieb, H. Vieker, A. Beyer, A. Gölzhäuser, H. Wang, K. Kohse-Höinghaus, Proc. Combust. Inst. 35 (2015) 1879-1886.

55. M.M. Maricq, J. Aerosol Sci. 38 (2007) 141-156.

56. Ü.Ö. Köylü, C. McEnally, D. Rosner, L. Pfefferle, Combust. Flame 110 (1997) 494-507.

57. R.I.A. Patterson, M. Kraft, Combust. Flame 151 (2007) 160-172.

58. A. Goldaniga, L. Zappella, T. Faravelli, M. Dente, E. Ranzi, in: Open meeting on Combustion XXIII Event of the Italian Section of the Combustion Institute, Ischia, Italy, May, 2000, pp 32.

59. K.H. Homann, H.G. Wagner, Proc. Combust. Inst. 11 (1967) 371-379.

60. J.P. Cain, P.L. Gassman, H. Wang, A. Laskin, Phys. Chem. Chem. Phys. 12 (2010) 5206-5218.

61. J.P. Cain, J. Camacho, D.J. Phares, H. Wang, A. Laskin, Proc. Combust. Inst. 33 (2011) 533-540. 
62. E. Ranzi, M. Dente, T. Faravelli, G. Pennati, Combust. Sci. Technol. 95 (1993) 1-50.

63. A. Violi, T.N. Truong, A.F. Sarofim, J. Phys. Chem. A 108 (2004) 4846-4852.

64. A. Goel, J.B. Howard, Carbon 41 (2003) 1949-1954.

65. H. Wang, M. Frenklach, Combust. Flame 110 (1997) 173-221.

66. J. Appel, H. Bockhorn, M. Frenklach, Combust. Flame 121 (2000) 122-136.

67. C. Cavallotti, D. Polino, Proc. Combust. Inst. 34 (2013) 557-564.

68. M.R. Djokic, K.M. Van Geem, C. Cavallotti, A. Frassoldati, E. Ranzi, G.B. Marin, Combust. Flame 161 (2014) 2739-2751.

69. H.-B. Zhang, X. You, H. Wang, C.K. Law, J. Phys. Chem. A 118 (2014) 1287-1292.

70. M. Rapacioli, F. Calvo, F. Spiegelman, C. Joblin, D. Wales, J. Phys. Chem. A 109 (2005) $2487-$ 2497.

71. A. D'Anna, J. Kent, Combust. Flame 144 (2006) 249-260.

72. N.A. Fuchs, The mechanics of aerosols, Dover Publications Inc., Mineola, NY, 1964.

73. A. D’Alessio, A. Barone, R. Cau, A. D’Anna, P. Minutolo, Proc. Combust. Inst. 30 (2005) 25952603.

74. A. Raj, M. Sander, V. Janardhanan, M. Kraft, Combust. Flame 157 (2010) 523-534.

75. M. Colket, D. Seery, Proc. Combust. Inst. 25 (1994) 883-891.

76. J. Emdee, K. Brezinsky, I. Glassman, J. Phys. Chem. 96 (1992) 2151-2161.

77. M. Sander, R.H. West, M.S. Celnik, M. Kraft, Aerosol Sci. Technol. 43 (2009) 978-989.

78. R.L. Vander Wal, A.J. Tomasek, Combust. Flame 134 (2003) 1-9.

79. N. Marinov, W. Pitz, C. Westbrook, A. Lutz, A. Vincitore, S. Senkan, Proc. Combust. Inst. 27 (1998) 605-613.

80. A.D. Abid, N. Heinz, E.D. Tolmachoff, D.J. Phares, C.S. Campbell, H. Wang, Combust. Flame 154 (2008) 775-788.

81. A. Gomez, D. Rosner, Combust. Sci. Technol. 89 (1993) 335-362.

82. N.A. Eaves, S.B. Dworkin, M.J. Thomson, Proc. Combust. Inst. 35 (2015) 1787-1794. 
Table I. Classes of lumped pseudo-species defined in the current work as BINs (PAHs, particles, and aggregates) and their properties: median mass, equivalent spherical diameter and $\mathrm{H} / \mathrm{C}$ ratio for particles; collision diameter and number of primary particles for each aggregate $\left(N_{p}\right)$.

\begin{tabular}{|c|c|c|c|c|c|c|}
\hline \multicolumn{7}{|c|}{ PAHs } \\
\hline \multirow[b]{2}{*}{$\mathbf{B I N}_{i}$} & \multirow[b]{2}{*}{$n_{C}$} & \multirow{2}{*}{$\begin{array}{l}\text { Median mass } \\
\text { [amu] }\end{array}$} & \multirow{2}{*}{$\begin{array}{c}\text { Diameter } \\
{[\mathrm{nm}]}\end{array}$} & \multicolumn{3}{|c|}{$\mathrm{H} / \mathrm{C}$} \\
\hline & & & & $\mathbf{A}$ & B & C \\
\hline$i=1$ & 20 & 250 & 0.81 & 0.8 & 0.5 & 0.3 \\
\hline 2 & 40 & 500 & 1.02 & 0.8 & 0.5 & 0.3 \\
\hline 3 & 80 & 1000 & 1.28 & 0.75 & 0.45 & 0.3 \\
\hline 4 & 160 & 2000 & 1.62 & 0.7 & 0.4 & 0.3 \\
\hline \multicolumn{7}{|c|}{ Particles } \\
\hline & & Median mass & Diameter & \multicolumn{3}{|c|}{ H/C } \\
\hline $\mathbf{B I N}_{i}$ & $n_{C}$ & [amu] & {$[\mathbf{n m}]$} & $\mathbf{A}$ & B & C \\
\hline$i=5$ & 320 & $4 \times 10^{3}$ & 2.04 & 0.65 & 0.35 & 0.2 \\
\hline 6 & 640 & $8 \times 10^{3}$ & 2.57 & 0.6 & 0.35 & 0.15 \\
\hline 7 & 1250 & $1.55 \times 10^{4}$ & 3.21 & 0.55 & 0.3 & 0.1 \\
\hline 8 & 2500 & $3 \times 10^{4}$ & 4.04 & 0.5 & 0.25 & 0.1 \\
\hline 9 & 5000 & $6 \times 10^{4}$ & 5.09 & 0.45 & 0.2 & 0.1 \\
\hline 10 & $1 \times 10^{4}$ & $1.2 \times 10^{5}$ & 6.40 & 0.4 & 0.15 & 0.1 \\
\hline 11 & $2 \times 10^{4}$ & $2.45 \times 10^{5}$ & 8.05 & 0.35 & 0.1 & \\
\hline 12 & $4 \times 10^{4}$ & $4.9 \times 10^{5}$ & 10.14 & 0.35 & 0.1 & \\
\hline \multicolumn{7}{|c|}{ Aggregates } \\
\hline & & Median mass & $\begin{array}{l}\text { Collision } \\
\text { diameter }\end{array}$ & & \multicolumn{2}{|c|}{$\mathrm{H} / \mathrm{C}$} \\
\hline $\mathbf{B I N}_{i}$ & $n_{C}$ & [amu] & {$[\mathrm{nm}]$} & $N_{p}$ & $\mathbf{A}$ & B \\
\hline$i=13$ & $8 \times 10^{4}$ & $9.7 \times 10^{5}$ & 13.27 & 2 & 0.3 & 0.1 \\
\hline 14 & $1.6 \times 10^{5}$ & $1.95 \times 10^{6}$ & 19.50 & 4 & 0.3 & 0.1 \\
\hline 15 & $3.2 \times 10^{5}$ & $3.9 \times 10^{6}$ & 28.63 & 8 & 0.25 & 0.1 \\
\hline 16 & $6.4 \times 10^{5}$ & $7.8 \times 10^{6}$ & 41.98 & 16 & 0.2 & 0.05 \\
\hline 17 & $1.25 \times 10^{6}$ & $1.51 \times 10^{7}$ & 60.89 & 32 & 0.2 & 0.05 \\
\hline 18 & $2.5 \times 10^{6}$ & $3.02 \times 10^{7}$ & 89.49 & 64 & 0.2 & 0.05 \\
\hline 19 & $5 \times 10^{6}$ & $6.02 \times 10^{7}$ & 131.53 & 128 & 0.2 & 0.05 \\
\hline 20 & $1 \times 10^{7}$ & $1.21 \times 10^{8}$ & 193.32 & 256 & 0.2 & 0.05 \\
\hline
\end{tabular}


Table II. Reaction classes in the soot model and their reference kinetic parameters.

\begin{tabular}{|c|c|c|c|c|c|}
\hline \multirow[b]{2}{*}{ Reactions and their classes } & \multicolumn{3}{|c|}{$k=A T^{n} \exp (-E / R T)^{\mathrm{a}}$} & \multirow[b]{2}{*}{ Refs. } & \multirow[b]{2}{*}{ Reference Reaction } \\
\hline & $A$ & $n$ & $E$ & & \\
\hline \multicolumn{6}{|l|}{ 1. HACA mechanism } \\
\hline \multicolumn{6}{|l|}{ 1a. H-abstraction } \\
\hline $\mathrm{H}+\mathrm{BIN}_{i} \rightarrow \mathrm{H}_{2}+\mathrm{BIN}_{i}^{\bullet}$ & $5.4 \times 10^{5}$ & 2 & 10.5 & {$[62,63]$} & $\mathrm{H}+\mathrm{BIN}_{5} \rightarrow \mathrm{H}_{2}+\mathrm{BIN}_{5} \bullet$ \\
\hline \multicolumn{6}{|l|}{ 1b. Acetylene addition } \\
\hline $\mathrm{C}_{2} \mathrm{H}_{2}+\mathrm{BIN}_{i} \bullet \rightarrow$ products & $1.0 \times 10^{9}$ & 0 & 5 & {$[65,66]$} & $\mathrm{C}_{2} \mathrm{H}_{2}+\mathrm{C}_{10} \mathrm{H}_{7} \rightarrow \mathrm{C}_{12} \mathrm{H}_{9} \bullet$ \\
\hline \multicolumn{6}{|l|}{ 2. Soot inception $(i, n<5)$} \\
\hline $\mathrm{BIN}_{i} \bullet+\mathrm{BIN}_{n} \bullet \rightarrow$ products & $1.0 \times 10^{9}$ & 0 & $6^{\mathrm{b}}$ & {$[67,68]$} & $\mathrm{C}_{5} \mathrm{H}_{5} \bullet+\mathrm{C}_{5} \mathrm{H}_{5} \bullet \rightarrow \mathrm{C}_{10} \mathrm{H}_{8}+2 \mathrm{H} \bullet$ \\
\hline $\mathrm{BIN}_{i}+\mathrm{BIN}_{n} \bullet \rightarrow$ products & $1.0 \times 10^{9}$ & 0 & $8^{b}$ & {$[68]$} & $\mathrm{C}_{6} \mathrm{H}_{5} \bullet+\mathrm{C}_{8} \mathrm{H}_{6} \rightarrow \mathrm{C}_{14} \mathrm{H}_{10}+\mathrm{H} \bullet$ \\
\hline $\mathrm{BIN}_{i}+\mathrm{BIN}_{n} \rightarrow$ products & $1.0 \times 10^{6}$ & 0.5 & 0 & {$[71]$} & $\mathrm{C}_{16} \mathrm{H}_{10}+\mathrm{C}_{16} \mathrm{H}_{10} \rightarrow$ products \\
\hline \multicolumn{6}{|l|}{ 3. Surface growth } \\
\hline \multicolumn{6}{|l|}{ 3a. Small RR・ } \\
\hline $\mathrm{RR} \bullet+\mathrm{BIN}_{i} \rightarrow$ products & $2.0 \times 10^{9}$ & 0 & $19^{\mathrm{b}}$ & {$[68]$} & $\mathrm{C}_{3} \mathrm{H}_{3} \bullet+\mathrm{C}_{6} \mathrm{H}_{6} \rightarrow \mathrm{C}_{9} \mathrm{H}_{8}+\mathrm{H} \bullet$ \\
\hline $\mathrm{RR} \bullet+\mathrm{BIN}_{i} \bullet \longrightarrow$ products & $2.5 \times 10^{9}$ & 0 & $3^{b}$ & [68] & $\mathrm{C}_{3} \mathrm{H}_{3} \bullet+\mathrm{C}_{6} \mathrm{H}_{5} \bullet \rightarrow \mathrm{C}_{9} \mathrm{H}_{8}$ \\
\hline \multicolumn{6}{|l|}{ 3b. PAHs } \\
\hline \multicolumn{6}{|l|}{$i \geq 5$} \\
\hline \multicolumn{6}{|l|}{$\mathrm{PAH} \bullet+\mathrm{BIN}_{i} \rightarrow$ products } \\
\hline $\begin{array}{l}i<5 \text { and } n \geq 5 \\
\mathrm{BIN}_{i} \bullet+\mathrm{BIN}_{n} \bullet \rightarrow \text { products } \\
\operatorname{BIN}_{i}+\mathrm{BIN}_{n} \bullet \rightarrow \text { products }\end{array}$ & $3.0 \times 10^{11}$ & 0.5 & 0 & This work & see text \\
\hline \multicolumn{6}{|l|}{ 4. Dehydrogenation } \\
\hline \multicolumn{6}{|l|}{ 4a. Dehydrogenation } \\
\hline $\mathrm{BIN}_{i} \bullet \rightarrow \mathrm{H} \bullet+\mathrm{BIN}_{i}$ & $1.0 \times 10^{11}$ & 0 & 12 & [15] & $\mathrm{C}_{13} \mathrm{H}_{11} \bullet \rightarrow \mathrm{C}_{13} \mathrm{H}_{10}+\mathrm{H} \bullet$ \\
\hline $\mathrm{BIN}_{i} \rightarrow \mathrm{H}_{2}+\mathrm{BIN}_{i}$ & $1.0 \times 10^{8}$ & 0 & 32 & {$[75]$} & $\mathrm{C}_{13} \mathrm{H}_{12} \rightarrow \mathrm{C}_{13} \mathrm{H}_{10}+\mathrm{H}_{2}$ \\
\hline \multicolumn{6}{|l|}{ 4b. Demethylation (for $\mathrm{H} / \mathrm{C}>0.3$ ) } \\
\hline $\mathrm{H} \bullet+\mathrm{BIN}_{i} \rightarrow \mathrm{CH}_{3} \bullet+$ products & $1.2 \times 10^{10}$ & 0 & 5 & [76] & $\mathrm{C}_{11} \mathrm{H}_{10}+\mathrm{H} \bullet \rightarrow \mathrm{C}_{10} \mathrm{H}_{8}+\mathrm{CH}_{3} \bullet$ \\
\hline \multicolumn{6}{|l|}{ 4c. $C$-H fission/recombination } \\
\hline $\mathrm{BIN}_{i} \rightarrow \mathrm{H} \bullet+\mathrm{BIN}_{i} \bullet$ & $1.5 \times 10^{17}$ & 0 & 114 & [42] & $\mathrm{C}_{6} \mathrm{H}_{6} \rightarrow \mathrm{C}_{6} \mathrm{H}_{5} \bullet+\mathrm{H}^{\bullet}$ \\
\hline $\mathrm{H} \bullet+\mathrm{BIN}_{i} \bullet \rightarrow \mathrm{BIN}_{i}$ & $1.0 \times 10^{11}$ & 0 & 0 & [42] & $\mathrm{C}_{6} \mathrm{H}_{5} \bullet+\mathrm{H} \bullet \rightarrow \mathrm{C}_{6} \mathrm{H}_{6}$ \\
\hline \multicolumn{6}{|l|}{ 5. Coalescence and aggregation } \\
\hline \multicolumn{6}{|l|}{ 5a. Coalescence $(5 \leq i, n<13)$} \\
\hline $\mathrm{BIN}_{i}+\mathrm{BIN}_{n} \rightarrow$ products & $2.0 \times 10^{11}$ & 0.5 & 0 & This work & see text \\
\hline \multicolumn{6}{|c|}{ 5b. Coalescence on aggregates $(5 \leq i<13$ and $n \geq 13)$} \\
\hline $\mathrm{BIN}_{i}+\mathrm{BIN}_{n} \rightarrow$ products & $1.5 \times 10^{11}$ & 0.5 & 0 & This work & see text \\
\hline \multicolumn{6}{|l|}{ 5c. Aggregation $(i, n \geq 13)$} \\
\hline $\mathrm{BIN}_{i}+\mathrm{BIN}_{n} \rightarrow$ products & $1.5 \times 10^{11}$ & 0.5 & 0 & This work & see text \\
\hline
\end{tabular}

\section{Oxidation}

\section{6a. Oxidation with $\mathrm{OH} \bullet$}

\begin{tabular}{|c|c|c|c|c|c|}
\hline $\mathrm{OH} \bullet+\mathrm{BIN}_{i} \rightarrow$ products $+\mathrm{CH}_{2} \mathrm{CO}$ & $1.0 \times 10^{10}$ & 0 & 10 & {$[65]$} & $\mathrm{OH} \bullet+\mathrm{C}_{16} \mathrm{H}_{10} \rightarrow \mathrm{C}_{14} \mathrm{H}_{9} \bullet+\mathrm{CH}_{2} \mathrm{CO}$ \\
\hline $\mathrm{OH} \bullet+\mathrm{BIN}_{i} \rightarrow$ products $+\mathrm{CO}+\mathrm{CH}_{3} \bullet$ & $1.0 \times 10^{10}$ & 0 & 4 & {$[15]$} & $\mathrm{OH} \bullet+\mathrm{C}_{11} \mathrm{H}_{10} \rightarrow \mathrm{C}_{9} \mathrm{H}_{8}+\mathrm{CO}+\mathrm{CH}_{3} \bullet$ \\
\hline 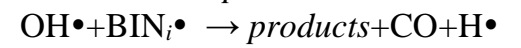 & $2.0 \times 10^{11}$ & 0 & 0 & {$[15]$} & $\mathrm{OH} \bullet+\mathrm{C}_{10} \mathrm{H}_{7} \bullet \rightarrow \mathrm{C}_{9} \mathrm{H}_{7} \bullet+\mathrm{CO}+\mathrm{H} \bullet$ \\
\hline $\mathrm{OH} \bullet+\mathrm{BIN}_{i} \rightarrow$ products $+\mathrm{HCO} \bullet$ & $3.0 \times 10^{9}$ & 0.5 & 10.6 & {$[71]$} & $\mathrm{OH} \bullet+\mathrm{C}_{10} \mathrm{H}_{8} \rightarrow \mathrm{C}_{9} \mathrm{H}_{8}+\mathrm{HCO} \bullet$ \\
\hline \multicolumn{6}{|l|}{ 6b. Oxidation with $O \bullet$} \\
\hline $\mathrm{O} \bullet+\mathrm{BIN}_{i} \rightarrow$ products $+\mathrm{HCCO} \bullet$ & $2.0 \times 10^{10}$ & 0 & 4 & {$[65]$} & $\mathrm{O} \bullet+\mathrm{C}_{16} \mathrm{H}_{10} \rightarrow \mathrm{C}_{14} \mathrm{H}_{9} \bullet+\mathrm{HCCO} \bullet$ \\
\hline $\mathrm{O} \bullet+\mathrm{BIN}_{i} \bullet \rightarrow$ products $+\mathrm{CO}$ & $5.0 \times 10^{10}$ & 0 & 0 & {$[15]$} & $\mathrm{O} \bullet+\mathrm{C}_{10} \mathrm{H}_{7} \bullet \rightarrow \mathrm{C}_{9} \mathrm{H}_{7} \bullet+\mathrm{CO}$ \\
\hline \multicolumn{6}{|l|}{ 6c. Oxidation with $\mathrm{O}_{2}$} \\
\hline $\mathrm{O}_{2}+\mathrm{BIN}_{i} \bullet \rightarrow$ products $+\mathrm{CO}+\mathrm{HCO} \bullet$ & $2.1 \times 10^{9}$ & 0 & 7.4 & {$[65]$} & $\mathrm{O}_{2}+\mathrm{C}_{10} \mathrm{H}_{7} \bullet \rightarrow \mathrm{C}_{8} \mathrm{H}_{6} \bullet+\mathrm{CO}+\mathrm{HCO} \bullet$ \\
\hline $\mathrm{O}_{2}+\mathrm{BIN}_{i} \bullet \rightarrow$ products $+\mathrm{O} \bullet+\mathrm{CO}$ & $2.6 \times 10^{10}$ & 0 & 6.12 & {$[15]$} & $\mathrm{O}_{2}+\mathrm{C}_{10} \mathrm{H}_{7} \bullet \rightarrow \mathrm{C}_{9} \mathrm{H}_{7} \bullet+\mathrm{O} \bullet+\mathrm{CO}$ \\
\hline $\mathrm{O}_{2}+\mathrm{BIN}_{i} \bullet \rightarrow$ products $+2 \mathrm{CO}$ & $4.2 \times 10^{8}$ & 0.5 & 8 & [71] & $\mathrm{O}_{2}+\mathrm{C}_{16} \mathrm{H}_{9} \bullet \rightarrow \mathrm{C}_{14} \mathrm{H}_{9} \bullet+2 \mathrm{CO}$ \\
\hline
\end{tabular}

${ }^{\mathrm{a}}$ Units are mol, L, s, K and kcal. ${ }^{\mathrm{b}}$ See text.

$\mathrm{RR} \bullet=\mathrm{C}_{3} \mathrm{H}_{3} \bullet, i-\mathrm{C}_{4} \mathrm{H}_{3} \bullet i-\mathrm{C}_{4} \mathrm{H}_{5} \bullet$, and $\mathrm{C}_{5} \mathrm{H}_{5} \bullet$ (cyclopentadienyl). PAH $\bullet$ = parent radicals of $\mathrm{C}_{6} \mathrm{H}_{6}, \mathrm{C}_{7} \mathrm{H}_{8}, \mathrm{C}_{6} \mathrm{H}_{5} \mathrm{C}_{2} \mathrm{H}_{2} \mathrm{C}_{6} \mathrm{H}_{5} \mathrm{C}_{2} \mathrm{H}_{3}, x_{1} x_{2}$, ethylbenzene, indene, $\mathrm{C}_{10} \mathrm{H}_{8}, \mathrm{C}_{10} \mathrm{H}_{7} \mathrm{CH}_{3}, \mathrm{C}_{12} \mathrm{H}_{8}, \mathrm{C}_{12} \mathrm{H}_{10}$, fluorine, diphenylmethane, $\mathrm{C}_{14} \mathrm{H}_{10}, \mathrm{C}_{14} \mathrm{H}_{14}$, and $\mathrm{C}_{16} \mathrm{H}_{10}$. 
Table III. Sensitivity test cases of rates of some selected reaction classes.

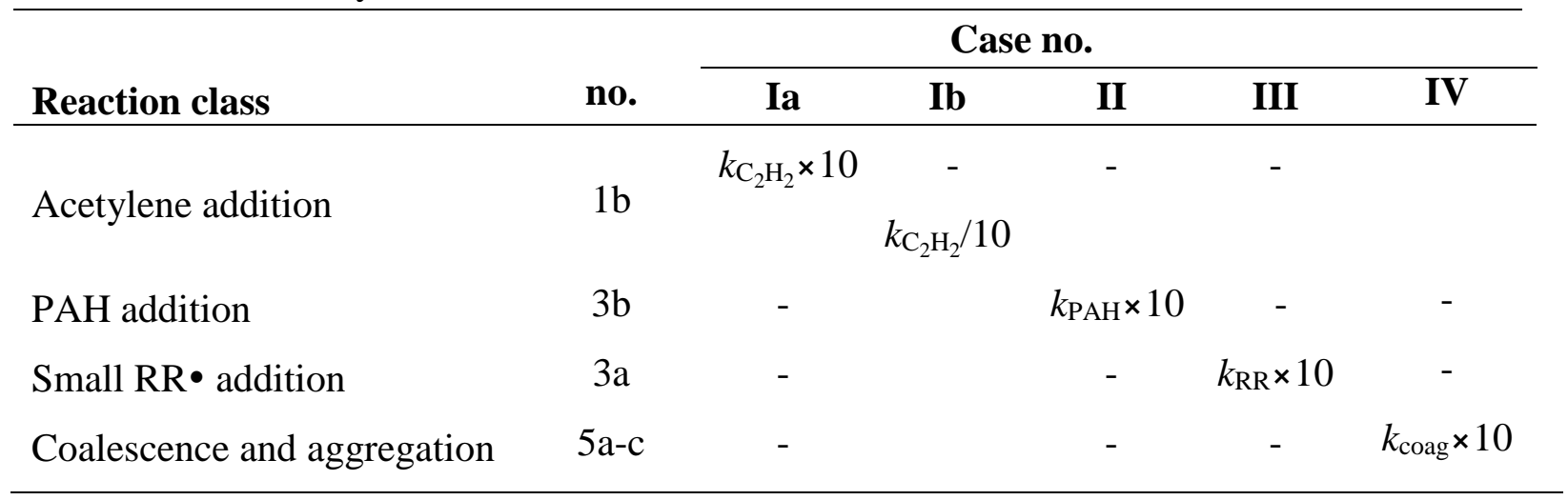

Table IV. Sensitivity test cases of coalescence and aggregation kinetics.

\section{Case no.}

\begin{tabular}{lcccc} 
Reaction class & no. & VI & VII & VIII \\
\hline $\begin{array}{l}\text { Coalescence } \\
\text { Coalescence on }\end{array}$ & $5 \mathrm{a}$ & $A_{5 \mathrm{a}}=8 \times 10^{11} \mathrm{l} /(\mathrm{mol} \cdot \mathrm{s})$ & - & - \\
$\begin{array}{l}\text { aggregates } \\
\text { Aggregation }\end{array}$ & $5 \mathrm{~b}$ & - & $A_{5 \mathrm{~b}}=5 \times 10^{11} \mathrm{l} /(\mathrm{mol} \cdot \mathrm{s})$ & - \\
\hline
\end{tabular}




\section{Figures captions}

Figure 1. Comparison between the $\mathrm{H} / \mathrm{C}$ ratio assigned to each $\mathrm{BIN}$ (lines with open symbols) and experimental data (filled symbols) [59]. $\mathrm{BIN}_{i ; A}$ (circles), $\mathrm{BIN}_{i ; B}$ (squares) and $\mathrm{BIN}_{i ; C}$ (triangles).

Figure 2. Frequency factor of the acetylene addition to aryl-radical site as a function of the BIN classes. The different symbols represent $\mathrm{BIN}_{i ; A}$ (circles), $\mathrm{BIN}_{i ; B}$ (triangles) and $\mathrm{BIN}_{i ; C}$ (squares).

Figure 3. Collision efficiency assumed for PAH radicals addition on soot, (reaction class 3b, line, eq. 7) compared to experimental data (symbols) [73].

Figure 4. Comparison between the collision efficiency of PAH radical addition on soot (reaction class 3b,eq. 7, solid line) and the collision efficiency for particle-particle coalescence (reaction class 5a, eq.8, dashed line) assumed in the model.

Figure 5. A schematic of the BSS flame (upper panel) [34] and comparison between modeled (solid lines) and measured (symbols) [40] axial temperature profiles of the BSS ethylene flame for a series of $H_{p}$ values (bottom panel). The dashed line at $H_{p}=1.0 \mathrm{~cm}$ is a simulation carried out neglecting radiative heat loss.

Figure 6. BSS flame profiles computed for the major species at $H_{p}=1.0 \mathrm{~cm}$ with (solid lines) and without (dashed lines) the Soret effect.

Figure 7. PAHs mole fraction profiles computed for the BSS flame at $H_{p}=1.0 \mathrm{~cm}$ with (solid lines) and without (dashed lines) the Soret effect.

Figure 8. Selected mole fraction profiles computed for particles with the Soret effect considered for gas-phase species and the thermophoretic effect for particles (solid lines), with only the Soret effect on gas-phase species (dotted lines), and without either effects (dashed lines).

Figure 9. Rate-of-production analysis for $H_{p}=1.0 \mathrm{~cm}$. The thickness of the line indicates the relative significance of the reaction pathways.

Figure 10. Comparison between the measured (symbols) [40] and model predictions of the soot volume fraction and number density from the BSS ethylene flame as a function of the burner-to-stagnation surface separation, (solid lines) and at $0.2 \mathrm{~cm}$ beneath the stagnation surface (dashed lines).

Figure 11. Comparison between the measured (symbols) [40] and model predictions (lines) of the mobility PSDFs in the BSS ethylene flame for a series of burner-to-stagnation surface separations at the stagnation surface (solid lines) and $0.2 \mathrm{~cm}$ beneath the stagnation surface (dashed lines).

Figure 12. Sensitivity the soot volume fraction (top panels) and number density (bottom panels) with respect to selected model parameters (Table III) for $H_{p}=0.55$ and $1.0 \mathrm{~cm}$.

Figure 13. Sensitivity of the PSDFs with respect to selected model parameters (Table III) at $H_{p}=0.55$ and $1.0 \mathrm{~cm}$. Symbols: experimental data [40]; lines: model predictions at the stagnation surface. 
Figure 14. Sensitivity of the soot volume fraction and number density with respect to coalescence and aggregation kinetics for $H_{p}=0.55$ and $1.0 \mathrm{~cm}$.

Figure 15. Sensitivity of the PSDFs with respect to coalescence and aggregation kinetics for $H_{p}=0.55$ and $1.0 \mathrm{~cm}$. Symbols: experimental data [40]; lines: model predictions at the stagnation surface. 


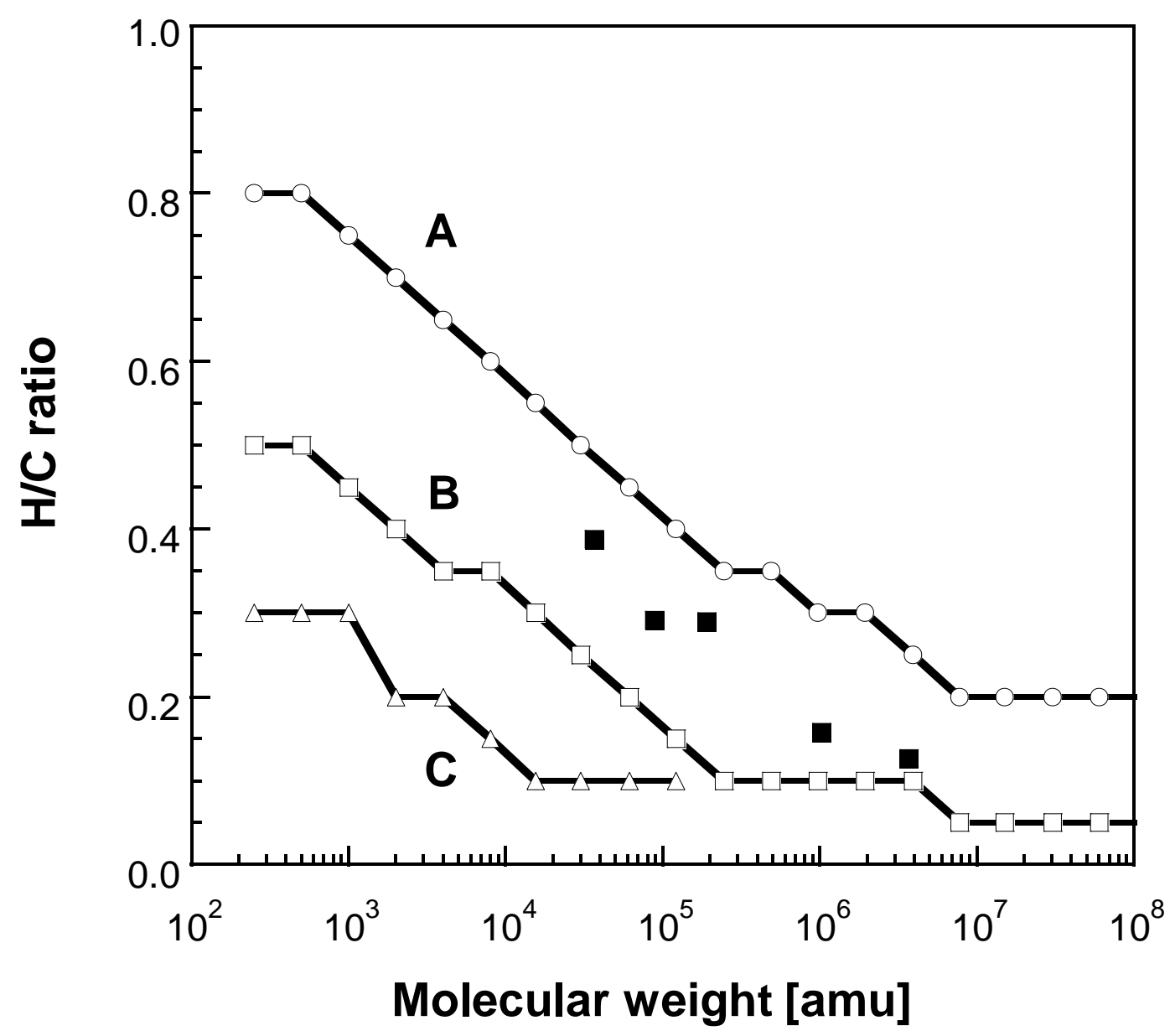

Figure 1. Comparison between the $\mathrm{H} / \mathrm{C}$ ratio assigned to each $\mathrm{BIN}$ (lines with open symbols) and experimental data (filled symbols) [59]. $\mathrm{BIN}_{i ; A}$ (circles), $\mathrm{BIN}_{i ; B}$ (squares) and $\mathrm{BIN}_{i ; C}$ (triangles). 


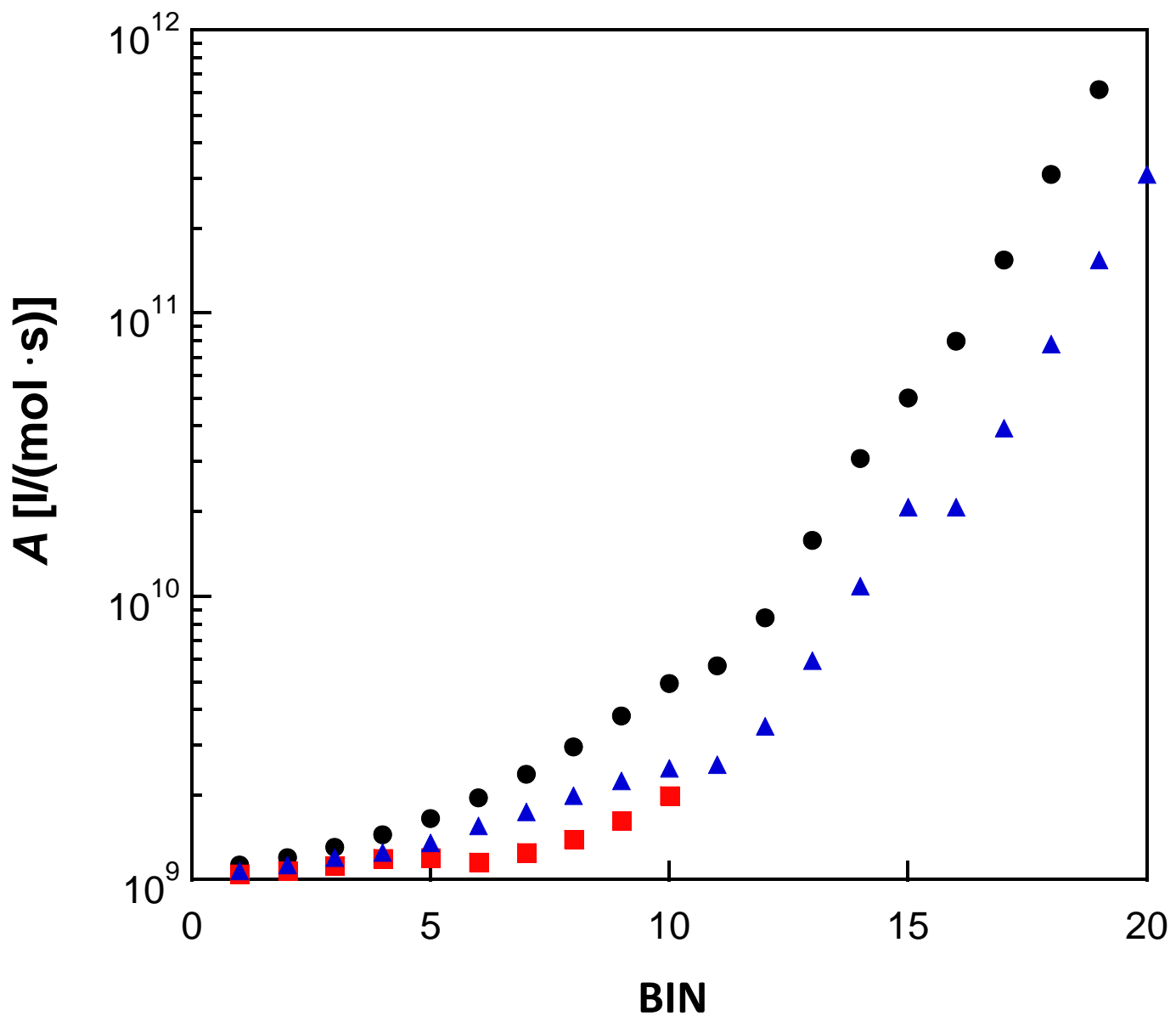

Figure 2. Frequency factor of the acetylene addition to aryl-radical site as a function of the BIN classes. The different symbols represent $\mathrm{BIN}_{i ; A}$ (circles), $\mathrm{BIN}_{i ; B}$ (triangles) and $\mathrm{BIN}_{i ; C}$ (squares). 


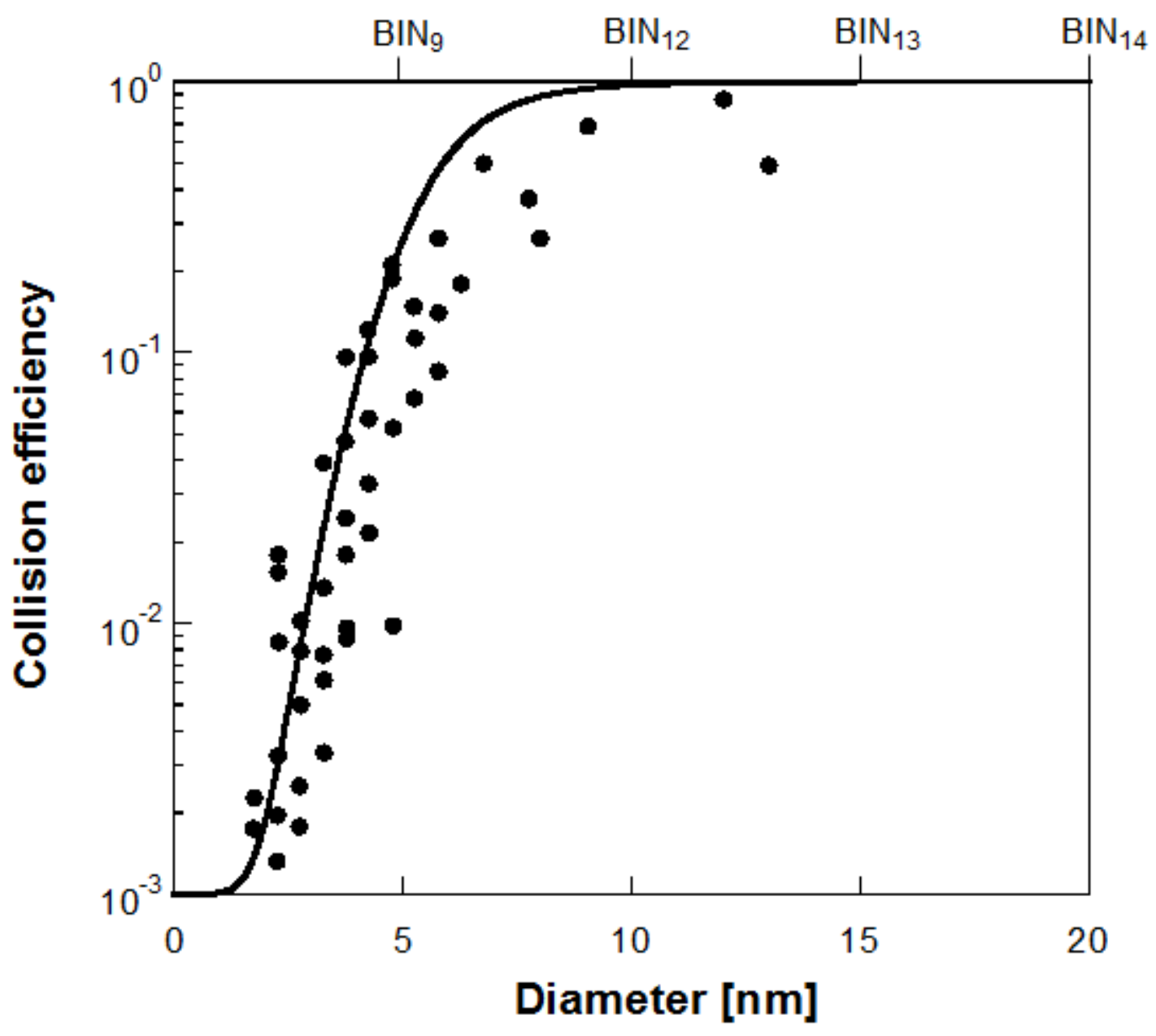

Figure 3. Collision efficiency assumed for PAH radicals addition on soot, (reaction class 3b, line, eq. 7) compared to experimental data (symbols) [73]. 


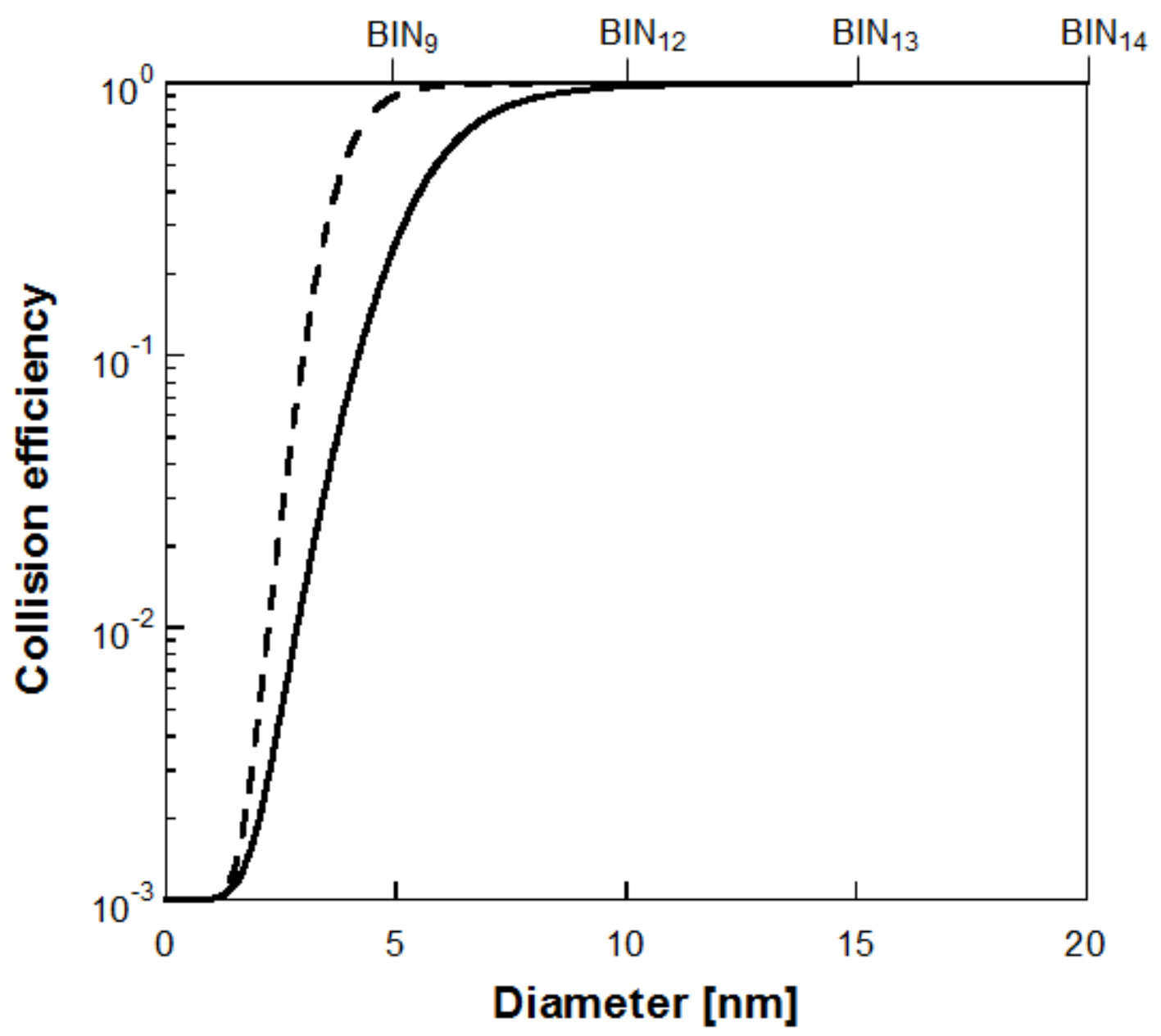

Figure 4. Comparison between the collision efficiency of PAH radical addition on soot (reaction class 3b, eq. 7, solid line) and the collision efficiency for particle-particle coalescence (reaction class 5a, eq.8, dashed line) assumed in the model. 

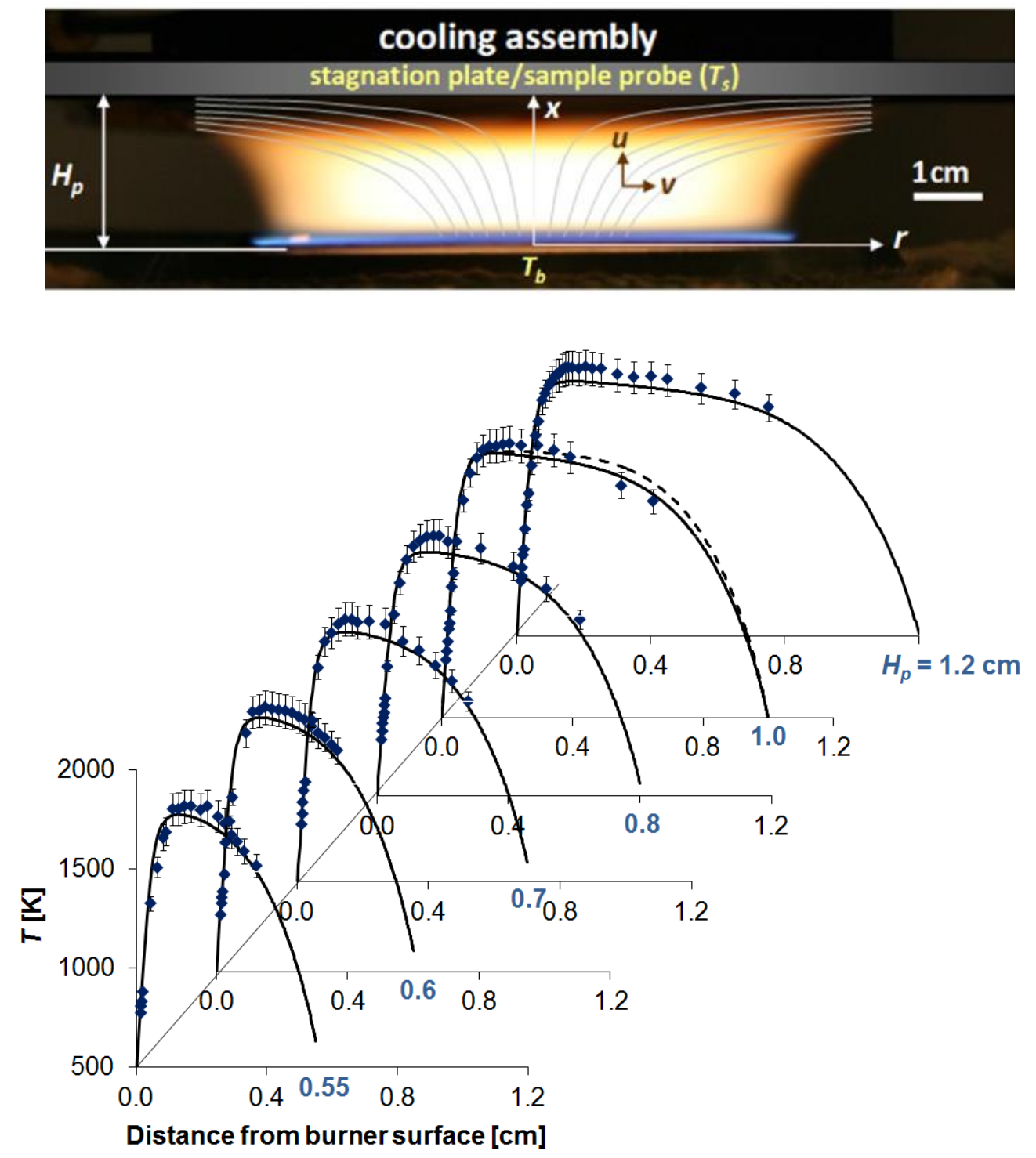

Figure 5. A schematic of the BSS flame (upper panel) [34] and comparison between modeled (solid lines) and measured (symbols) [40] axial temperature profiles of the BSS ethylene flame for a series of $H_{p}$ values (bottom panel). The dashed line at $H_{p}=1.0 \mathrm{~cm}$ is a simulation carried out neglecting radiative heat loss. 


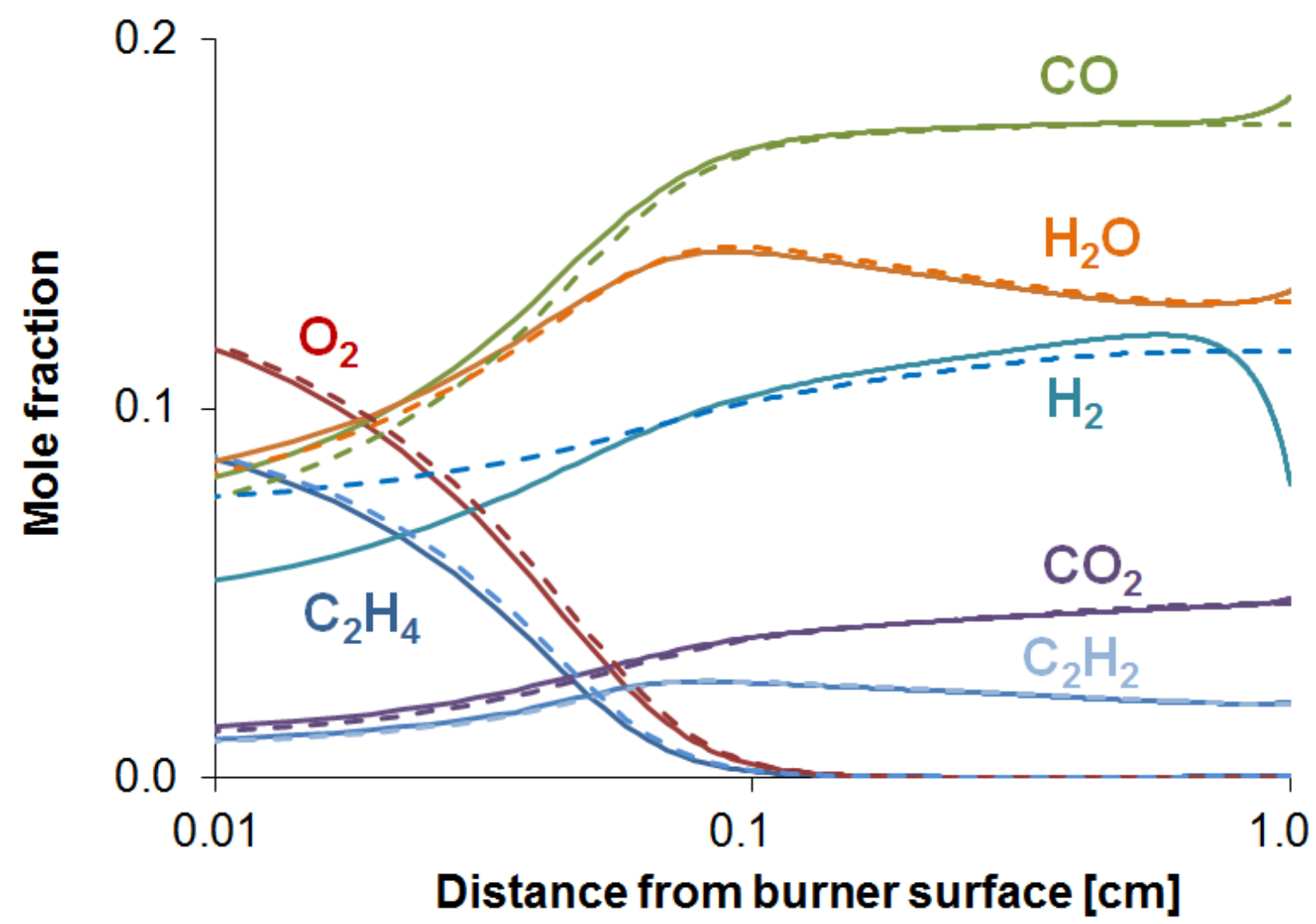

Figure 6. BSS flame profiles computed for the major species at $H_{p}=1.0 \mathrm{~cm}$ with (solid lines) and without (dashed lines) the Soret effect. 

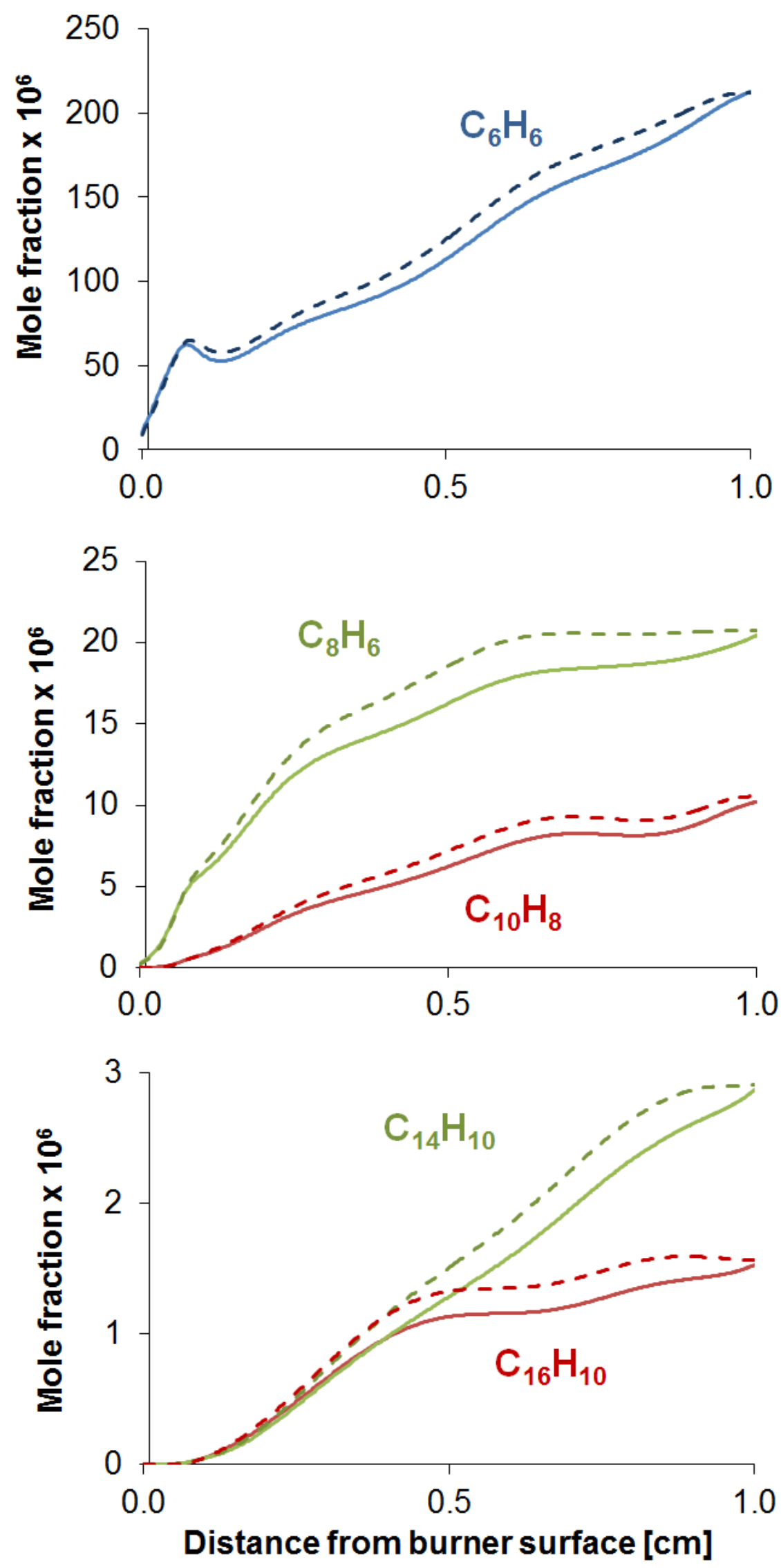

Figure 7. PAHs mole fraction profiles computed for the BSS flame at $H_{p}=1.0 \mathrm{~cm}$ with (solid lines) and without (dashed lines) the Soret effect. 

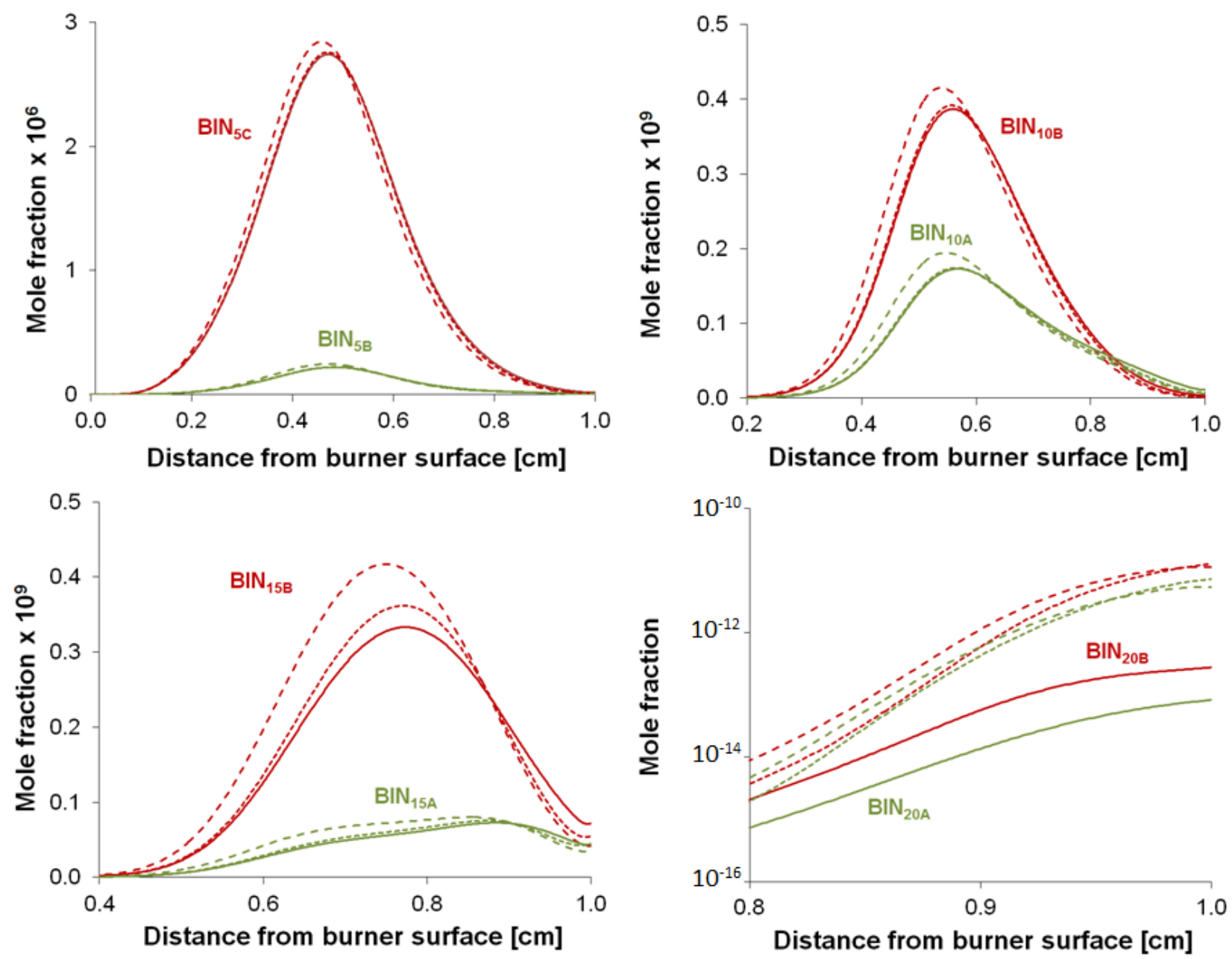

Figure 8. Selected mole fraction profiles computed for particles with the Soret effect considered for gas-phase species and the thermophoretic effect for particles (solid lines), with only the Soret effect on gas-phase species (dotted lines), and without either effects (dashed lines). 


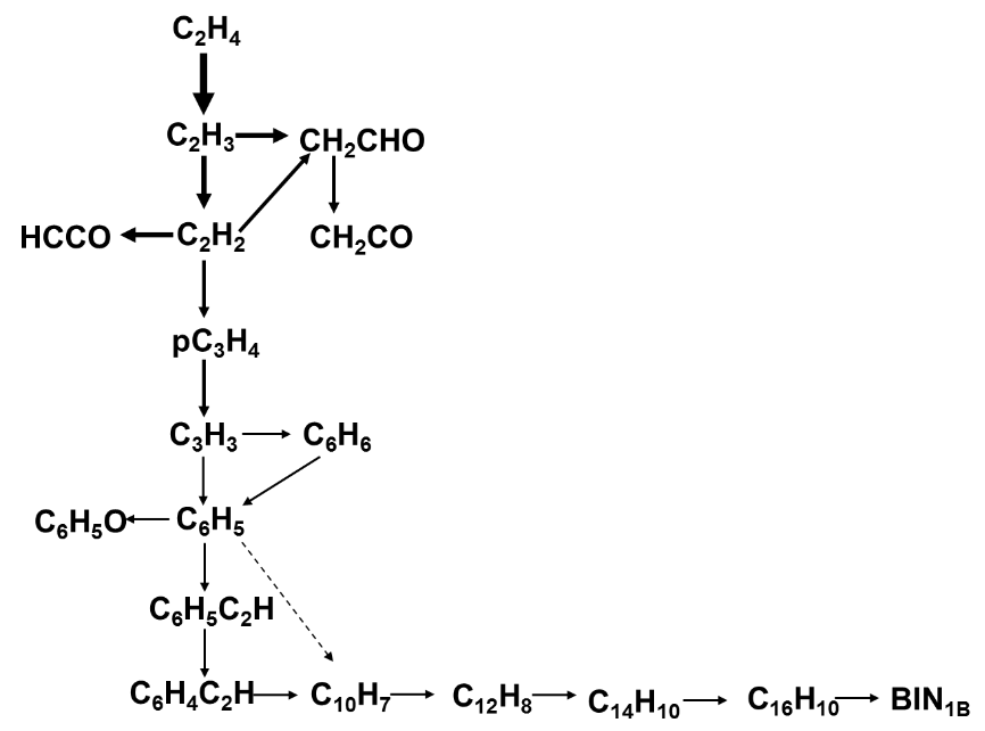

Figure 9. Rate-of-production analysis for $H_{p}=1.0 \mathrm{~cm}$. The thickness of the line indicates the relative significance of the reaction pathways.
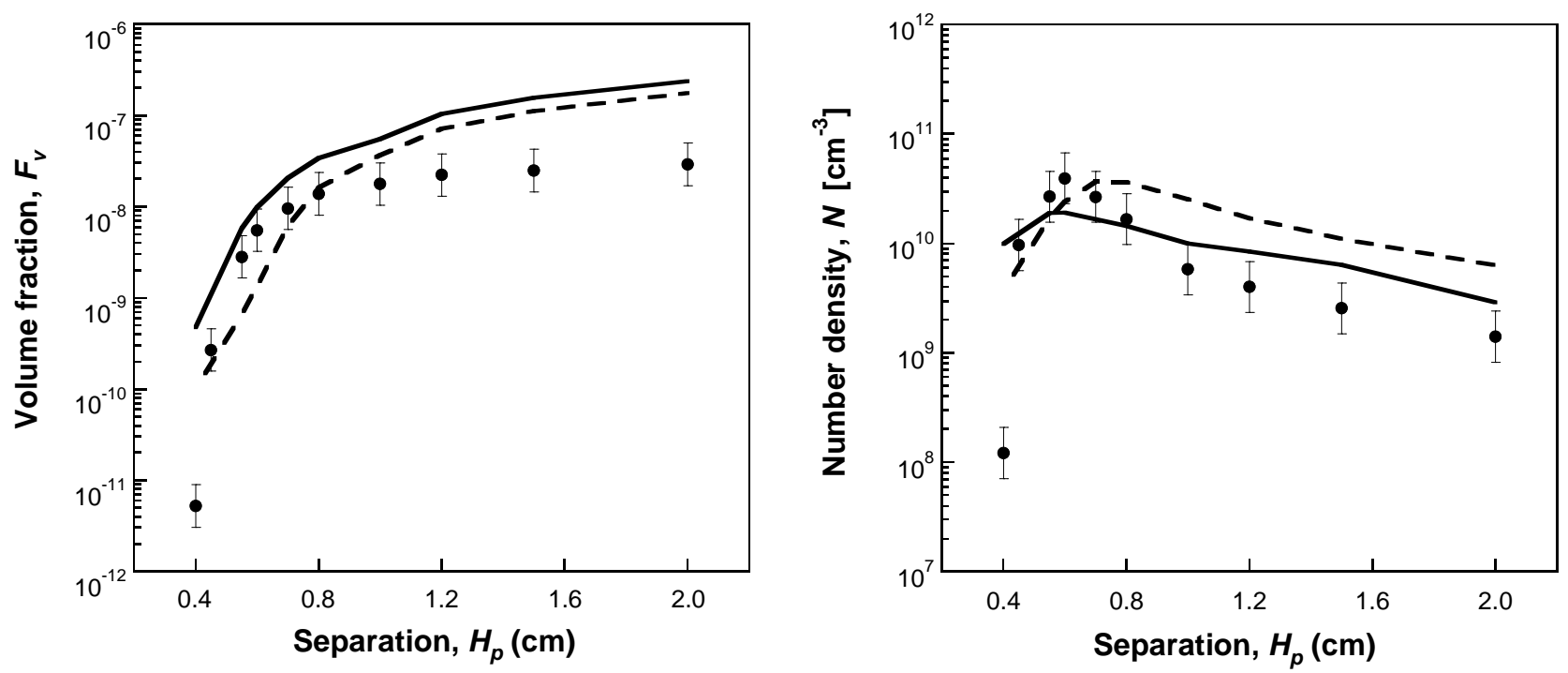

Figure 10. Comparison between the measured (symbols) [40] and model predictions of the soot volume fraction and number density from the BSS ethylene flame as a function of the burner-to-stagnation surface separation, (solid lines) and at $0.2 \mathrm{~cm}$ beneath the stagnation surface (dashed lines). 

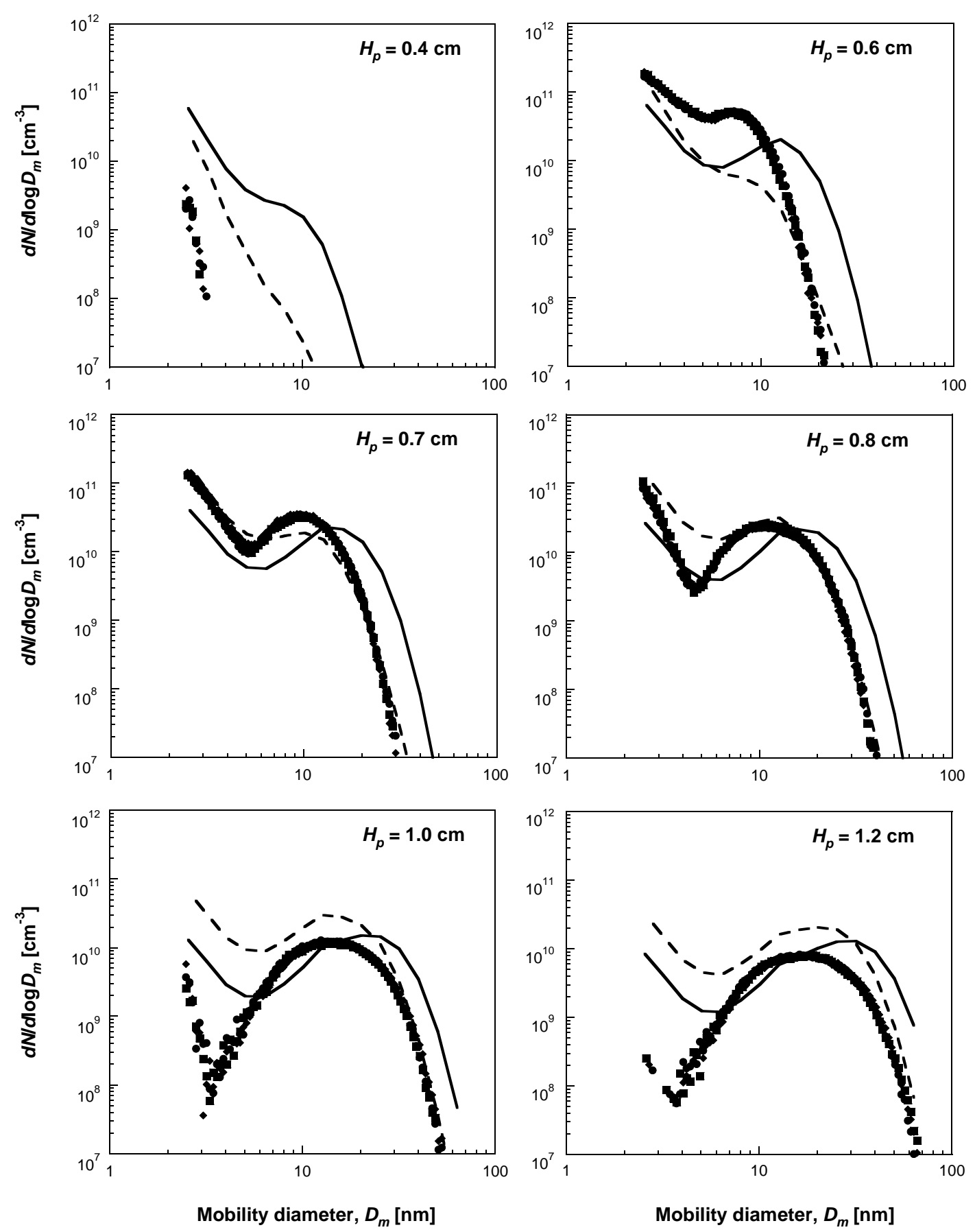

Figure 11. Comparison between the measured (symbols) [40] and model predictions (lines) of the mobility PSDFs in the BSS ethylene flame for a series of burner-to-stagnation surface separations at the stagnation surface (solid lines) and $0.2 \mathrm{~cm}$ beneath the stagnation surface (dashed lines). 

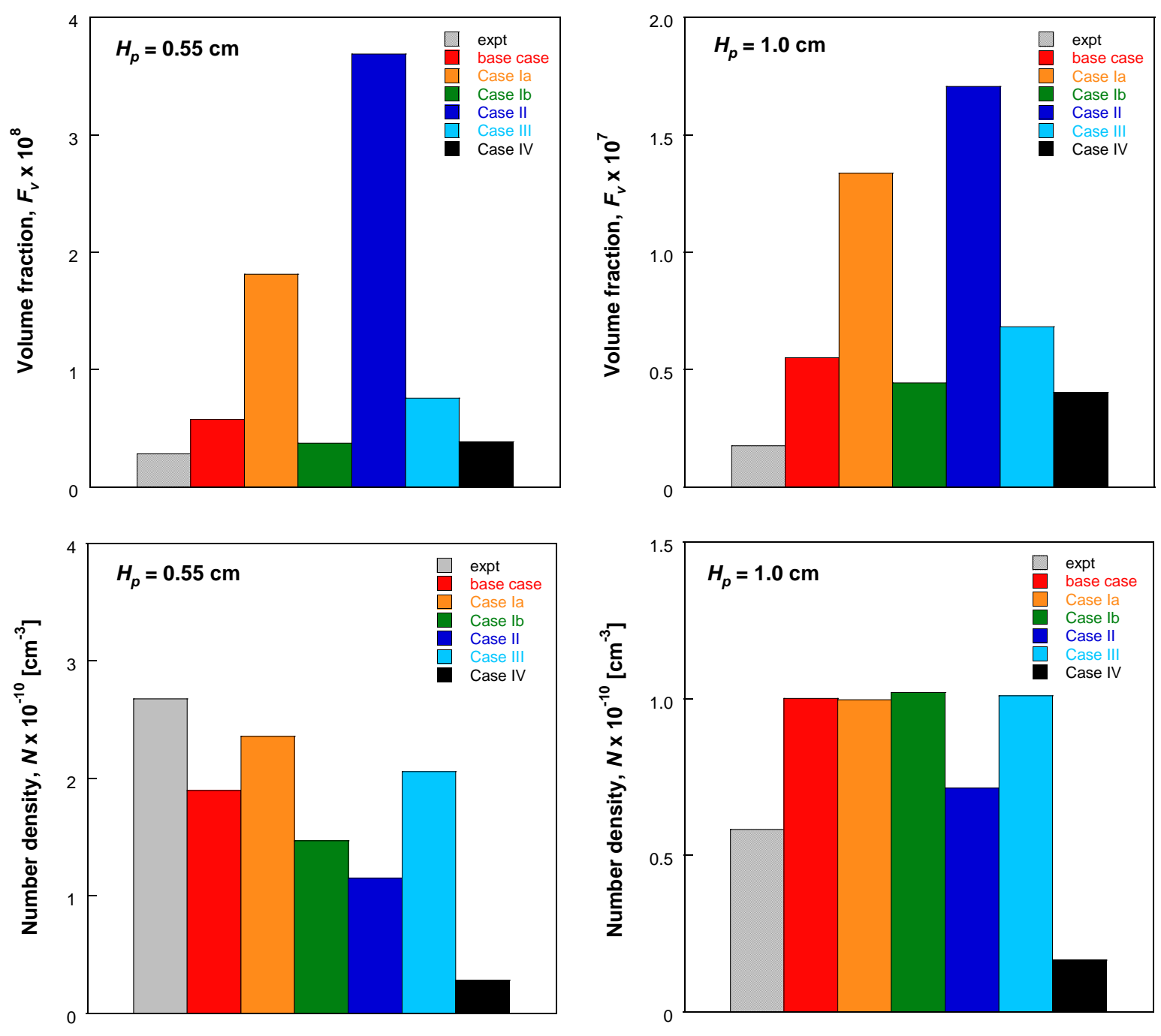

Figure 12. Sensitivity the soot volume fraction (top panels) and number density (bottom panels) with respect to selected model parameters (Table III) for $H_{p}=0.55$ and $1.0 \mathrm{~cm}$. 

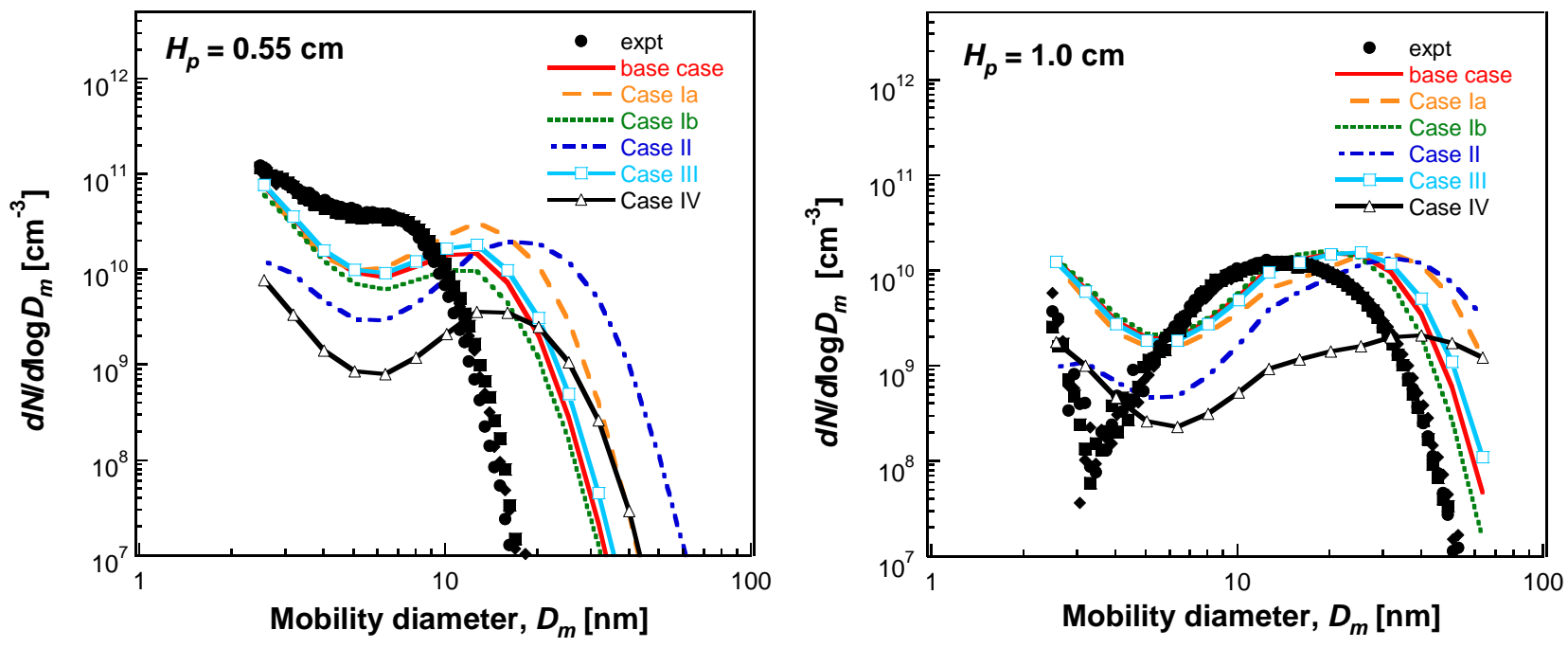

Figure 13. Sensitivity of the PSDFs with respect to selected model parameters (Table III) at $H_{p}=0.55$ and $1.0 \mathrm{~cm}$. Symbols: experimental data [40]; lines: model predictions at the stagnation surface. 

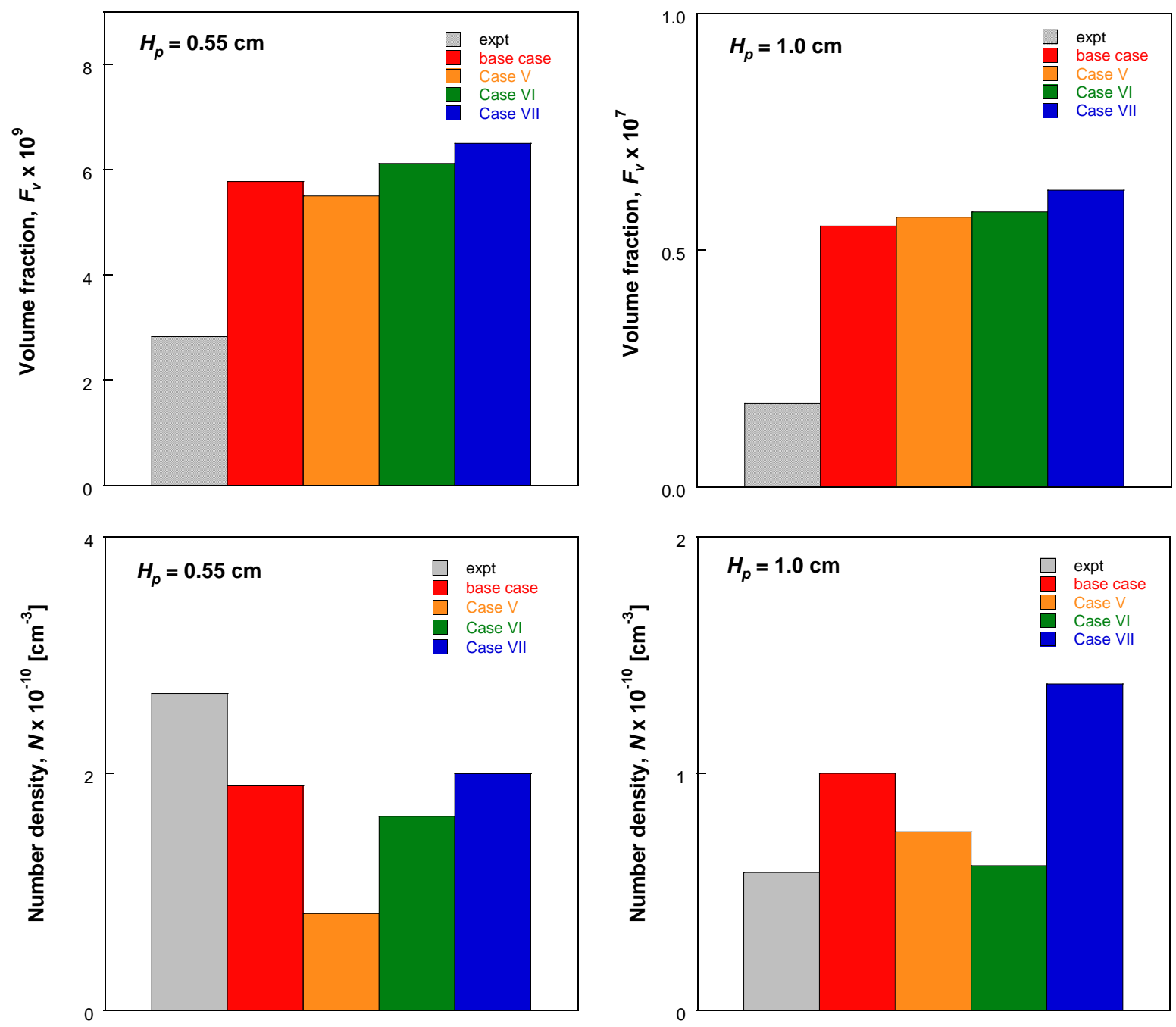

Figure 14.Sensitivity of the soot volume fraction and number density with respect to coalescence and aggregation kinetics for $H_{p}=0.55$ and $1.0 \mathrm{~cm}$. 

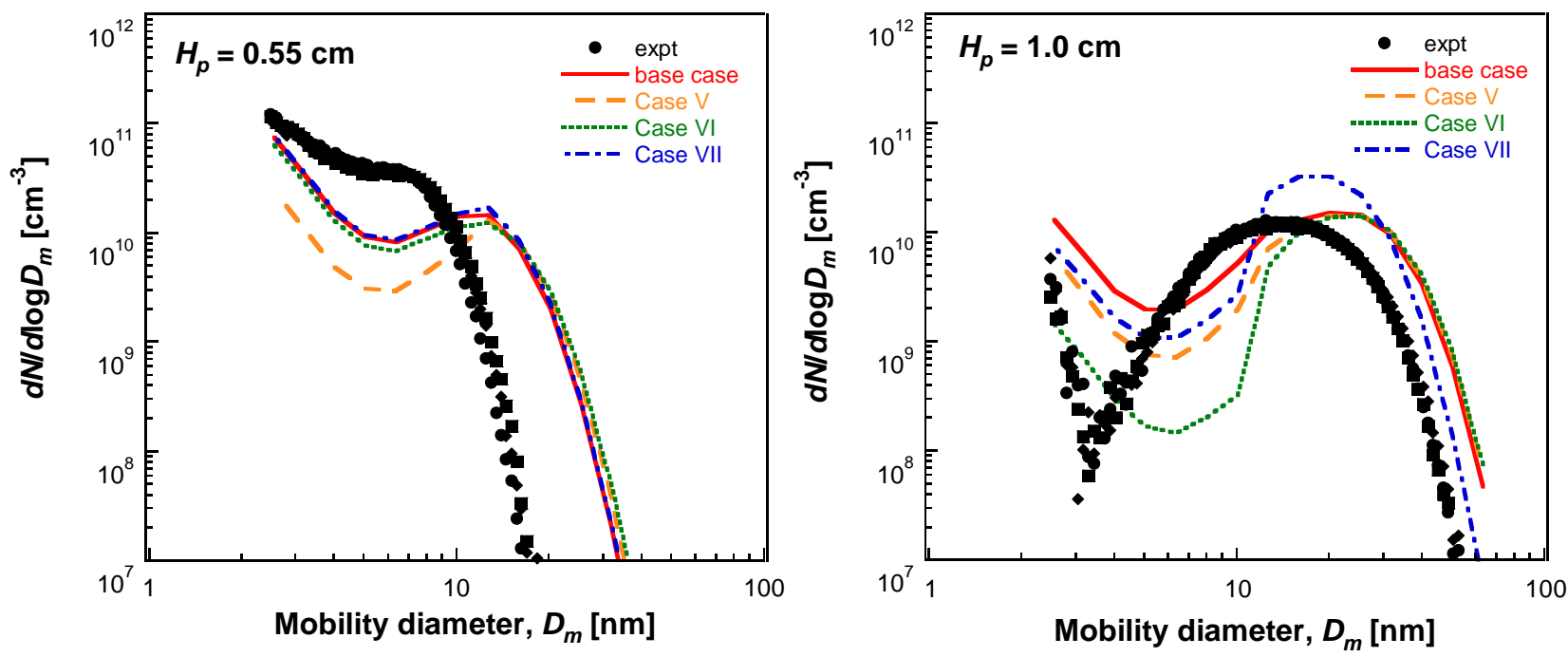

Figure 15. Sensitivity of the PSDFs with respect to coalescence and aggregation kinetics for $H_{p}=0.55$ and $1.0 \mathrm{~cm}$. Symbols: experimental data [40]; lines: model predictions at the stagnation surface. 